\title{
Teletrabajo docente durante el confinamiento por COVID-19 en Argentina. Condiciones materiales y perspectivas sobre la carga de trabajo, la responsabilidad social y la toma de decisiones Teachers' Telework During the COVID-19 Lockdown in Argentina. Material Conditions and Perspectives on Workload, Social Responsibility and Decision Making
}

Analía Inés Meo y Valeria Dabenigno'

\section{Resumen}

En Argentina las medidas para enfrentar la pandemia del COVID-19 incluyeron la suspensión de las clases presenciales en todos los niveles educativos y la implementación de una política de continuidad educativa. El objetivo de este artículo es analizar, por un lado, cuáles han sido las condiciones materiales y temporales del teletrabajo docente al inicio del confinamiento. Por el otro, examinar las percepciones docentes respecto del grado de participación en la toma de decisiones respecto de su tarea remota mediada por TIC; la carga mental que el teletrabajo forzado implicó; y su responsabilidad frente al sostenimiento de las trayectorias educativas de sus estudiantes. Nuestro abordaje se nutre de la perspectiva de Condiciones y Medio Ambiente de Trabajo y de estudios recientes sobre el teletrabajo. Los hallazgos de este estudio se basan en una encuesta en línea realizada a 678 docentes secundarios en el Área Metropolitana de Buenos Aires a fines de abril y principios de mayo. Mostramos que se ha dado un proceso de ampliación de la jornada laboral, en un contexto de fuertes desigualdades de condiciones materiales básicas de los/as docentes y diferentes tipos de culturas institucionales (en términos de participación docente en la toma de decisiones, clima de trabajo y experiencia previa en el uso de TIC), que ha impactado negativamente en la carga mental de más de la mitad de los/as docentes — aunque sin todavía mellar la confianza de la mayoría de los/as docentes respecto de su capacidad de acompañar a sus estudiantes.

\section{Palabras clave}

Teletrabajo, docente, confinamiento, condiciones de trabajo, escuela secundaria, Argentina, COVID-19.

\section{Abstract}

In Argentina educational policies dealing with the effects of COVID-19 have encompassed the lockdown of schools in every compulsory educational level and the National Ministry of Education's demands to all provinces to guarantee the continuation of schooling. This article examines, on the one hand, material conditions and time organisation of secondary school teachers' telework at the beginning of the confinement. On the other hand, it explores teachers' perceptions about their participation in the decision-making process that regulated their work, their views on the mental workload that the emergency and forced telework implied, and their social responsibility towards educational inclusion. To do so, it examines the results of an online survey applied to 678 secondary school teachers from the Metropolitan Area of Buenos Aires, which was carried out at the end of April and at the beginning of May. This piece evidences an increase of work time, in a context of teachers' material inequalities and diverse institutional cultures (in terms of teachers' participation, work climate and schools' previous pedagogic use of TIC), which has impacted on teachers' mental workload without significantly eroding their trust in school's ability to educationally support their students.

\section{Keywords}

Telework, teacher, confinement, working conditions, secondary school , Argentina, COVID-19.

\section{Cómo citar/Citation}

Meo, Analía Inés y Dabenigno, Valeria (2020). Teletrabajo docente durante el confinamiento por COVID-19 en Argentina. Condiciones materiales y perspectivas sobre la carga de trabajo, la responsabilidad social y la toma de decisiones. Revista de Sociología de la Educación-RASE, 14(1), 103-127. http://dx.doi.org/10.7203/RASE.14.1.18221. 


\section{Introducción}

Como en la mayoría de los países del mundo, en la Argentina las medidas para enfrentar la pandemia del COVID-19 incluyeron la suspensión de las clases presenciales en todos los niveles educativos desde el 20 de marzo alterando de maneras inéditas e inesperadas los modos en que autoridades, docentes, estudiantes y familias hacían la escuela cotidianamente. Desde la segunda semana del confinamiento, la política educativa nacional estableció como horizonte deseable garantizar la continuidad educativa de todos/as los/as alumnos/as de los diferentes niveles educativos de escolaridad obligatoria. Entre estos lineamientos no había referencias a la virtualización de la enseñanza como obligatoria. Sus iniciativas incluían desde la distribución de cuadernillos, creación de programas de radio y televisión para dar clase, hasta recursos en línea gratuitos. Sin embargo, diversas investigaciones muestran que esta política fue vivida por muchas autoridades y docentes de distintas jurisdicciones como un imperativo de virtualización de las acciones pedagógicas, como una demanda a la que había que dar respuesta (Meo, 2020; CTERA, 2020).

La política de continuidad pedagógica sustentada en el uso de TIC (tecnologías de la información y la comunicación) fue puesta en acto en jurisdicciones como la de la Ciudad Autónoma de Buenos Aires (CABA) y de la provincia de Buenos Aires (PBA) afectando el trabajo de la gran mayoría de los/as docentes, quienes se vieron obligados/as a usar TIC en sus interacciones con autoridades, docentes, adolescentes y familias, y a hacerlo desde sus hogares con sus propios recursos tecnológicos, en tiempos y espacios ajenos a lo escolar (tanto para ellos/as como para sus estudiantes) (CTERA, 2020; ME-UNICEF, 2020).

Al inicio del confinamiento decidimos llevar adelante una encuesta en línea a docentes secundarios del Área Metropolitana de Buenos Aires para empezar a mapear este inédito escenario al inicio del Aislamiento Social Preventivo y Obligatorio (ASPO). Nuestro objetivo era conocer cuáles eran las características que estaba asumiendo esta modalidad de trabajo docente — a la cual llamamos «teletrabajo forzado en el hogar». Se trata de una forma de teletrabajo porque implica el uso de TIC para la realización remota de aspectos centrales del trabajo, el cual se desarrolla en los hogares de los/as trabajadores y es puesto en marcha sin la expresa voluntad de las partes involucradas (empleados/as ni empleadores). Nuestra encuesta indagó condiciones de vida, acciones educativas, modos de vincularse con estudiantes y colegas, así como percepciones sobre desafíos, problemas y aprendizajes.

Este artículo focalizará su atención en, por un lado, las condiciones materiales y temporales del teletrabajo docente de emergencia iniciado con el confinamiento. Prestamos atención a los niveles de equipamiento básico y disponibilidad de espacio aislado de trabajo, así como a las percepciones acerca de la ampliación del tiempo laboral y del grado de conciliación con el tiempo atribuido a las tareas y responsabilidades domésticas y de cuidado. Por el otro, examina las perspectivas de los/as docentes en torno a tres aspectos centrales del teletrabajo de emergencia: i) el grado de participación en la toma de decisiones respecto de su tarea remota mediada por TIC; ii) la carga mental y psíquica o psicoafectiva negativa o positiva que el teletrabajo forzado implicó; y iii) su responsabilidad respecto de la acción educativa que se pudo desplegar para sostener las trayectorias educativas de sus estudiantes en este primer momento del ASPO. En cada uno de estos aspectos se examinarán variaciones de acuerdo al tipo de escuela en la que trabaja, y a características laborales, atributos socio-demográficos y configuraciones familiares de los/as docentes. Interesa indagar la presencia de segmentaciones entre tipos de escuelas, y condiciones de vida docente.

Este trabajo se organiza en un primer apartado conceptual y de antecedentes, seguido por una sección que describe el contexto geográfico de la investigación y características del estudio realizado. Seguida- 
Teletrabajo docente durante el confinamiento por COVID-19 en Argentina. Condiciones materiales y perspectivas sobre la carga de trabajo, la responsabilidad social y la toma de decisiones

mente, el análisis se presentará en dos subsecciones: condiciones materiales y temporales del teletrabajo docente forzado, y sus condiciones sociales y psicosociales — a partir del rastreo de percepciones y emociones que han tenido acerca de su trabajo y sus relaciones con pares, autoridades y estudiantes.

\section{Analizando el trabajo y el teletrabajo docente: enfoque y antecedentes}

El estudio del trabajo docente en los niveles obligatorios de la educación ha convocado a especialistas del trabajo (de la sociología, psicología y antropología) y a organizaciones sindicales quienes, en su gran mayoría, han examinado las condiciones de trabajo en el espacio físico escolar. Pocos estudios han prestado atención a docentes que trabajan como teletrabajadores o en los aspectos del trabajo docente que se vienen realizando a distancia y con ayuda de las TIC. La irrupción de la pandemia y el ASPO ha generado condiciones laborales inéditas. En este apartado, mapeamos hallazgos de investigaciones y reconoceremos claves conceptuales que nos han permitido reconocer aspectos significativos del impacto de lo que hemos llamado «teletrabajo docente forzado». Para ello, trabajamos con dos corpus de producciones: el enfoque de las Condiciones y Medio Ambiente de Trabajo (CyMAT) y sus aportes al estudio del trabajo docente, y los estudios del teletrabajo.

\section{1. Las CyMAT como enfoque multidimensional}

El enfoque de las CyMAT comienza a utilizarse en Argentina en la década de 1980, como una perspectiva superadora del paradigma de higiene y seguridad en el trabajo. Hasta ese momento, primaba una concepción que interpretaba los accidentes laborales primordialmente desde la «teoría del factor humano», la cual enfatizaba el error o propensión al accidente por parte del trabajador, atomizando e individualizando sus causas (Neffa, 1988). Contrariamente, la perspectiva CyMAT busca prevenir y eliminar los riesgos laborales de trabajadores/as, situando el análisis en factores multidimensionales y supraindividuales que forman parte del proceso de trabajo y condiciones sociotécnicas de producción, contemplando elementos objetivos y subjetivos. Asume la heterogeneidad de capacidades de resistir y adaptarse al medio y por ello busca captar sus experiencias y vivencias (Neffa, 1988, Giraudo et al., 2003).

Desde las CyMAT se considera que existe una carga global del trabajo prescripto, entendida como las exigencias, requerimientos y limitaciones que el puesto de trabajo impone al trabajador (Neffa, 1988). La carga global está compuesta por exigencias físicas, psíquicas y cognitivas para cumplir con una tarea (Giraudo et al., 2003). La física contempla los esfuerzos musculares, las posturas y movimientos corporales que exige la actividad desarrollada. La mental alude al esfuerzo cognitivo de la actividad relativo a la cantidad y complejidad de información percibida, captada y procesada en una unidad de tiempo. Esta carga se expresa en la intensidad de las tareas (velocidad exigida o cantidad de productos o servicios generados en un tiempo); y la complejidad definida según la cantidad de decisiones y esfuerzos cognitivos de atención y concentración (Giraudo et al., 2003). Finalmente, la carga psíquica trata los aspectos psicosociales, relacionales y afectivos de la actividad desempeñada que afectan la vida de los trabajadores/as. Se trata de analizar si la actividad ofrece un mínimo de variación o la posibilidad de iniciativa y autonomía, si estimula procesos de aprendizaje y trabajo colaborativo entre pares y miembros de organización, si tiene reconocimiento social y es vista como una contribución al futuro (Giraudo et al., 2003). Estas dimensiones de la carga de trabajo van unidas y deberían ser equilibradas, por eso cuando se habla de sobrecarga se hace referencia a la «nociva preponderancia» de un aspecto 
sobre los otros. A su vez, esta carga prescripta tiene consecuencias sobre la vida y salud física, psíquica y/o mental de quien trabaja.

Son numerosos los estudios sobre condiciones de trabajo docente. Entre los estudios CyMAT se destaca una encuesta sobre Condiciones de Trabajo y Salud Docente en seis países latinoamericanos (UNESCO, 2005). Para el caso argentino, se evidencian largas jornadas laborales signadas por fatiga y desgaste laboral, falta de descansos, tiempos excesivos de traslado entre escuelas y hogar y condiciones de infraestructura escolar deficitarias. Se destacan también las exigencias «ergonómicas» de estar muchas horas de pie y alzando la voz en las clases. En cuanto a las vivencias, priman sentimientos de soledad en la tarea, con problemas vinculares entre docentes, directivos y familias, pero cooperación entre pares ante demandas estudiantiles y reclamos edilicios y gremiales. Se concluye también sobre la discrepancia entre alta autovaloración y baja valoración social y de las familias de alumnos/as sobre el rol docente en la sociedad. Otro estudio desde el abordaje CyMAT es el de Dirié y Pascual (2011) que trabaja con fuentes de datos secundarias (Censos docentes y Encuestas a Hogares) para hacer un diagnóstico de algunos aspectos materiales del trabajo docente en la provincia de Buenos Aires, fundamentalmente del tiempo de trabajo semanal y características del puesto, identificando cambios positivos en la primera década del siglo (mayor protección laboral y mejoras salariales). Sin inscripción tan directa en las CyMAT, otras investigaciones coinciden en recuperar la perspectiva de los actores — satisfacción laboral, reivindicaciones, niveles de compromiso, reconocimiento social percibido, entre otros aspectos - para hablar de las condiciones laborales docentes (Zamora Begoña, 2011). Otro conjunto de estudios no solo se preocupa por mapear las condiciones laborales sino en identificar sus efectos en el rendimiento y aprendizajes de estudiantes (UNESCO, 2005; Bascia y Rottman, 2011), así como en la rotación de puesto de trabajo (Burkhauser, 2017; Geiger y Pirovarova, 2018; Ladd, 2011), y en la propensión a aceptar la innovación escolar (Cucchiara et al., 2015).

Finalmente, encontramos algunos trabajos académicos y realizados por organizaciones gremiales que examinan el trabajo docente en pandemia. Examinan los efectos de la emergencia en la organización del tiempo y su impacto negativo en la vida familiar, en la salud, en la intensificación del trabajo, y en el tipo de tarea pedagógica desempeñada por docentes, en particular, en sus relaciones con alumnos/as de diferentes niveles educativos (CTERA, 2020, ME, 2020). Otros estudios también examinan estrategias, recursos pedagógicos digitales y tecnológicos utilizados por docentes durante el confinamiento y evidenciaron crecientes demandas de capacitación en TIC (Ardini et al., 2020) así como la profundización de desigualdades socioeducativas entre estudiantes (Expósito y Marsollier, 2020) y entre condiciones de trabajo docente (ME 2020, Ardini et al., 2020).

\subsection{El teletrabajo como lente analítica}

Las condiciones de trabajo excepcionales durante el ASPO exigen buscar herramientas conceptuales y antecedentes de investigación que nos ayuden a entender la dimensión remota y mediada por TIC del trabajo docente que se impuso como modalidad de organizar la tarea de la gran mayoría de los/as docentes. Los estudios sobre el teletrabajo (T'T) nos brindan claves en esa dirección.

El TT como forma de organización laboral empezó a funcionar en la década de 1970 en Estados Unidos y en Europa (Guaca et al., 2018). Se trató inicialmente de una respuesta de empresas que - motivadas por la crisis energética - buscaron reducir costos en el procesamiento de datos en un 
escenario de reorganización de los modos de acumulación capitalista a nivel global y de difusión del uso de la computadora personal y de la telemática. En América Latina esta modalidad empezó a crecer a fines de los 90 en empresas transnacionales cuyas casas matrices la usaban como práctica laboral común (AIT, 2017). En el 2017 la media europea del TT era de 17\% y en Estados Unidos del 20\% (Eurofound - ILO, 2017). En América Latina, hay pocos datos sobre el número de teletrabajadores/as (AIT, 2018). En Argentina, no existen estudios específicos sobre el T'T a nivel nacional pero algunas estimaciones sostienen que el 2,7\% lo son (AIT, 2017).

El término TT (telecommuting en EE. UU. o telework en Europa) es utilizado con variaciones en distintos campos de producción académica — tales como ciencias empresariales y administración, y sociología del trabajo-, de políticas laborales, y en los medios de comunicación (Fernández-Tapia y Bravo Salazar, 2019; Jiménez Bernardino, 2013). Más allá de las particularidades que su uso asume, este término se refiere a formas de organizar y realizar el trabajo a distancia mediante el uso de TIC, con o sin contacto cara a cara con trabajadores (Conner et al., 1994). La deslocalización espacial puede implicar el trabajo en el hogar del trabajador/a, en telecentros de empresas, en centros de recursos compartidos, etc., (Rocha y Amador, 2019). Afecta a trabajadores muy diferentes, tales como empleados (de grandes corporaciones o de Pymes), profesionales, trabajadores autónomos y empleados de agencias estatales. La mayoría de las investigaciones sobre TT estudia empresas.

Tres grupos de trabajos han estudiado el teletrabajo (TT): los que sostienen visiones optimistas sobre sus efectos, los análisis pesimistas y los críticos (Rocha y Amador, 2018; Fernández-Tapia y Bravo Salazar, 2019). El primer grupo — la mayoría dentro de ciencias empresariales y administraciónidentifica al T'T como una modalidad que conlleva variedad de beneficios. Entre ellos: flexibilidad en el uso del tiempo, mejor conciliación entre el tiempo laboral y familiar (sobre todo de las mujeres), mayor autonomía para organizar el trabajo, facilitar tareas de cuidado, y reducir tiempo dedicado a transportarse. En esta perspectiva, el T'T es visto como beneficioso también para las empresas por el incremento de la productividad; y para la sociedad por la reducción de la contaminación, del consumo de energía y de los desplazamientos en la ciudad (De Luis et al., 2006; Silva, 2000; Tremblay, 2003). Un segundo grupo identifica al TT como una forma de organización laboral en sintonía con la expansión global del capitalismo contemporáneo, la flexibilización laboral que implica y la inercia tecnológica. Los estudios identifican variedad de efectos negativos del TT, relativos a: i) las dificultades de conciliar el tiempo laboral, personal y familiar, los conflictos que esto genera y el aumento de estrés asociado; ii) el ocultamiento de la doble jornada laboral de las mujeres y el reforzamiento de desigualdades de género; ii) la asunción de costos laborales por los/as propios trabajadores/as (tales como costos de guardería, limpieza, electricidad, compra de equipos, etc.); iii) la intensificación del trabajo y extensión de la jornada laboral no remunerada debido a la organización de las tareas según objetivos; iv) los mayores niveles de control de la empresa o de autosubordinación y autocontrol por parte de los/as trabajadores/as; v) la necesidad de aprender nuevas herramientas para realizar el T'T, sin que esto redunde en aumento de remuneraciones; vii) el aislamiento de los TT al eliminar formas de sociabilidad con pares: viii) la mayor desprotección legal de los trabajadores por ausencia o carácter insuficiente de marcos normativos; y ix) los efectos negativos en la salud. La tercera colección de investigaciones ha identificado tanto ventajas como desventajas y apunta a las vinculaciones del TT con procesos económicos y tecnológicos globales y sus relaciones con procesos de desigualdad social y exclusión. Argumentan que es necesario reconocer las particularidades de la práctica en distintos escenarios para 
Teletrabajo docente durante el confinamiento por COVID-19 en Argentina. Condiciones materiales y perspectivas sobre la carga de trabajo, la responsabilidad social y la toma de decisiones

poder mapear discursos y prácticas prestando atención a las perspectivas de diferentes actores (tales como agentes gubernamentales, empleadores, y trabajadores) (Cifuentes Leiton, 2020, Rodríguez y D’Errico, 2019, Miano, 2012).

\section{Políticas educativas y conectividad en el área metropolitana de Buenos Aires (AMBA) y contextualización de nuestro estudio}

El AMBA es una unidad territorial urbana que incluye a la Ciudad Autónoma de Buenos Aires (CABA) y a 40 municipios de la provincia de Buenos Aires (según el Censo de Población de 2010 contaba con 14800000 habitantes). Durante la pandemia, los gobiernos nacional y los jurisdiccionales desplegaron políticas sanitarias tomando a este aglomerado como un área que se comporta de manera unificada, debido a los altos niveles de circulación y conectividad de personas, bienes y servicios y a que es del territorio que concentra la mayor cantidad de contagios y decesos por COVID-19 (Chequeado, 2020). En esta sección, realizamos primero una caracterización educativa de este territorio para reconocer algunos de los grandes desafíos con los que debieron enfrentarse los/as docentes cuando cerraron sus escuelas debido a la pandemia. Seguidamente presentamos nuestra investigación.

Desde 2006 la educación secundaria es obligatoria (Ley 26.206) y en el territorio del AMBA se imparte en 3018 escuelas que conforman dos subsistemas con diferente estructura, tamaño y composición sectorial: el nivel secundario de CABA tiene 501 unidades de servicio con planes de 5 y 6 años, mientras el del Conurbano de la provincia tiene 2517 secundarias de 6 o 7 años; en su conjunto, más de la mitad de las escuelas del AMBA son de gestión estatal (53\%). En estas escuelas hay más de 60 mil cargos docentes y 1706947 horas cátedra docentes. En cuanto a los/as estudiantes, la matrícula del nivel secundario en el conjunto del AMBA es de 388096 alumnos/as, con peso mayoritario del sector estatal (61\%) (ME, 2018). Si bien no hay estadísticas oficiales recientes para el total del AMBA, existen serios problemas de infraestructura escolar y edilicia. Según el Censo de Infraestructura Escolar 2017 de CABA, solo 56\% de edificios escolares cuentan con todos los servicios básicos, $59 \%$ tiene factores de riesgo y apenas un tercio cumple con todas las medidas de seguridad (Quintero et al., 2019). En el Conurbano también los problemas edilicios son cuantiosos, pero no cuantificados por estadísticas actualizadas, con eventos recientes trágicos tales como la explosión de una escuela entera por pérdidas de gas (SA, 2019), que generaron movilizaciones de comunidades educativas y demandas crecientes de gremios docentes solicitando planes de prevención del riesgo.

En cuanto a las políticas desarrolladas al inicio del ASPO, los ministerios de educación nacional, de la CABA y de la PBA convergieron en una política de continuidad educativa, que se desplegó bajo los lemas «Seguimos educando» a nivel nacional, «Mi Escuela En Casa» en CABA y «Continuamos educando» en la Provincia de Buenos Aires. El Ministerio de Educación nacional, por ejemplo, puso a disposición un portal de acceso gratuito con contenidos para estudiantes y docentes, se produjeron programas de televisión y radio, así como cuadernos con actividades (en papel y formato digital). Los ministerios de educación de las dos jurisdicciones coincidieron en la adopción de variedad de estrategias para sostener la escolaridad secundaria y garantizar la llamada «continuidad pedagógica» (Di Piero y Miño Chiappino, 2020; Cardini et al., 2020). Sus ministerios de educación propusieron plataformas de recursos, materiales y propuestas educativas para estudiantes y docentes del nivel. En PBA se recuperan contenidos de la plataforma virtual «Seguimos educando», a diferencia de CABA que propone una comunicación directa con docentes, estudiantes y familias a través de aulas virtuales con actividades por año y nivel educativo, recursos en una 
biblioteca digital y secuencias didácticas a partir de una plataforma preexistente de gestión escolar — «mi Escuela».

Varios estudios locales muestran que el mayor desafío de la continuidad pedagógica fueron los altos déficits de equipamiento informático y conectividad de alumnos/as y familias (CTERA, 2020, ME-UNICEF, 2020). En cuanto al acceso a TIC de los hogares, el déficit de conectividad fue el punto de partida con el que tuvieron que trabajar los/las docentes de escolaridad obligatoria. Es así que 38\% de los hogares no tenían ni una sola computadora y solo 1 de cada 4 contaba con un equipo para cada niña, niño y adolescente del hogar. El otro recurso clave durante el ASPO ha sido la conectividad a Internet y la calidad de la señal: solo 55\% de los hogares del AMBA contaban con acceso fijo y buena calidad en la señal, mientras que el $20 \%$ no disponía de acceso fijo en sus hogares.

A principios de abril del corriente año, a pocas semanas de haberse iniciado el ASPO, elaboramos ${ }^{2}$ una encuesta a docentes de nivel secundario con el objetivo de conocer condiciones de vida, acciones educativas, modos de vincularse con estudiantes y colegas, así como las percepciones sobre desafíos, preocupaciones y aprendizajes relativos a su trabajo. Se trató de una encuesta autoadministrada y en línea. Ante la situación de excepción, nos decidimos por una estrategia de investigación ágil que nos permitiera reconocer algunos patrones y correlaciones emergentes. El instrumento incluyó 56 preguntas. Combinó preguntas abiertas, con respuestas únicas, múltiples y escalas de acuerdo y frecuencia en base a ítems especificados. En este artículo utilizamos los bloques de preguntas con información sociodemográfica, sobre el cargo docente, la composición del hogar, la disposición de espacio aislado y computadora de uso exclusivo, la distribución de las tareas de cuidado y del hogar en las familias, la jornada laboral, el clima de trabajo institucional (incluyendo uso previo de TIC y modalidades que adoptó la toma de decisiones durante el ASPO), y las percepciones y emociones respecto del tipo de demandas laborales que se les hacía a los/as docentes. El diseño de la muestra no fue probabilístico por el tipo de instrumento y por los propósitos del estudio. Se diseminó con una estrategia de «bola de nieve», con un gran esfuerzo en diversificar contactos entre diferentes jurisdicciones, sectores de gestión y organizaciones sindicales. Contestaron la encuesta 678 docentes del AMBA. Si bien los resultados no son representativos, la muestra tiene algunos patrones estructurales relativamente comparables con las distribuciones por sexos y edades que arroja el Censo Nacional Docente 2014 de Argentina (ver Tabla I, Anexo 1) (Dabenigno et al., 2020).

A continuación, analizamos los resultados relativos a las condiciones materiales y temporales de la tarea docente, para luego adentrarnos en el tratamiento de aspectos relativos a las vivencias del teletrabajo durante el inicio del confinamiento.

\section{Condiciones materiales y temporales del teletrabajo docente de emergencia}

Las condiciones materiales de desempeño del trabajo remoto serán analizadas en este apartado considerando dos aspectos: el acceso a recursos básicos para el teletrabajo en los hogares y la duración de la jornada laboral durante el ASPO. Siguiendo al enfoque de las CYMAT, ambos aspectos tienen efectos en la exigencia cognitiva y mental del teletrabajo.

2 El cuestionario fue elaborado por las autoras junto con Ada Freytes Frey (Universidad de Avellaneda), Aina Tarabini y Judith Jacovkis (ambas de la Universidad Autónoma de Barcelona). Agradecemos a Ada por sus comentarios durante una primera formulación de este trabajo. También a los/as revisores anónimos de este artículo por sus aportes y sugerencias. Esta investigación fue parcialmente financiada por la Secretaría de Ciencia y Técnica de la Universidad de Buenos Aires (proyecto «Las identidades laborales docentes en tiempos de fragmentación educativa. Un estudio de casos en la Ciudad de Buenos Aires», dirigido por Analía Meo y co-dirigido por Valeria Dabenigno. 
En contexto de educación remota de emergencia, la disponibilidad de equipamiento informático y espacio de trabajo en el hogar aparecen como condiciones básicas de posibilidad del teletrabajo. Nuestro relevamiento muestra que a inicios del confinamiento más de la mitad de los/as docentes (54\%) contaba con computadora de uso exclusivo y tenía en su hogar un espacio aislado para trabajar; en tanto, un tercio de los encuestados declaraba contar con solo uno de esos recursos, y un 13\% no contaba con ninguno. Los niveles de acceso a computadora y de disponibilidad de espacio físico están levemente asociados con el sector de gestión, siendo los/as docentes de escuelas privadas quienes se encuentran en mejor situación relativa ( $58 \%$ versus 50\% para el caso del sector estatal). En cambio, la asociación es más débil con el nivel socioeconómico (NSE) del alumnado de sus escuelas ( $58 \%$ de los/as docentes de escuelas con NSE medio o más tienen ambos recursos, valor que es 6 puntos porcentuales (pp.) menor entre docentes de escuelas de NSE más bajo) (Tabla I).

\section{Tabla I. Tenencia de computadora de uso exclusivo y de espacio aislado según sector de gestión, NSE, género, hogares con miembros con riesgo COVID-19, nivel de responsabilidad doméstica y de cuidado y tipo de hogar. Docentes de nivel secundario del Área Metropolitana, 2020}

\begin{tabular}{|c|c|c|c|c|c|c|c|c|c|c|c|c|c|c|c|}
\hline \multirow[b]{2}{*}{$\begin{array}{c}\text { TENENCIA DE } \\
\text { COMPUTADORA } \\
\text { Y DISPONIBILIDAD } \\
\text { DE ESPACIO }\end{array}$} & \multirow[b]{2}{*}{ 흠 } & \multicolumn{2}{|c|}{$\begin{array}{l}\text { SECTOR DE } \\
\text { GESTIÓN }\end{array}$} & \multicolumn{2}{|c|}{$\begin{array}{l}\text { NIVEL } \\
\text { SOCIOECONÓMICO } \\
\text { (NSE) }\end{array}$} & \multicolumn{2}{|c|}{ GÉNERO } & \multicolumn{5}{|c|}{$\begin{array}{l}\text { HOGARES CON NIVEL DE RESPONSABILIDAD } \\
\text { RIESGO COVID-19 DOMÉSTICA Y DE CUIDADO }\end{array}$} & \multicolumn{3}{|c|}{ TIPO DE HOGAR } \\
\hline & & 离 & 足 & 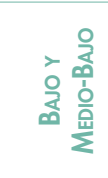 & 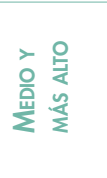 & 䓛 & $\begin{array}{l}\stackrel{0}{z} \\
\text { 总 } \\
\sum\end{array}$ & 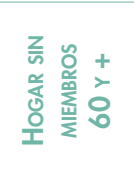 & 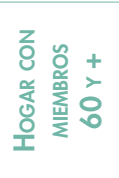 & 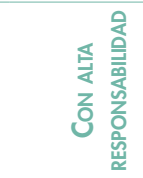 & 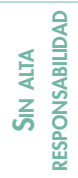 & 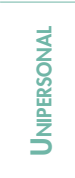 & 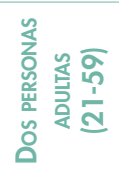 & 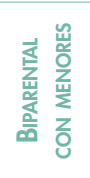 & 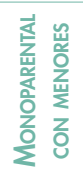 \\
\hline $\begin{array}{l}\text { Con computadora } \\
\text { y espacio aislado }\end{array}$ & $54 \%$ & $50 \%$ & $58 \%$ & $52 \%$ & $58 \%$ & $54 \%$ & $55 \%$ & $56 \%$ & $50 \%$ & $39 \%$ & $58 \%$ & $75 \%$ & $50 \%$ & $46 \%$ & $49 \%$ \\
\hline $\begin{array}{l}\text { Con una de ambas } \\
\text { condiciones }\end{array}$ & $32 \%$ & $35 \%$ & $29 \%$ & $35 \%$ & $28 \%$ & $31 \%$ & $35 \%$ & $32 \%$ & $34 \%$ & $37 \%$ & $31 \%$ & $23 \%$ & $37 \%$ & $33 \%$ & $23 \%$ \\
\hline $\begin{array}{l}\text { Sin Computadora } \\
\text { ni espacio aislado }\end{array}$ & $13 \%$ & $15 \%$ & $12 \%$ & $13 \%$ & $14 \%$ & $15 \%$ & $10 \%$ & $12 \%$ & $16 \%$ & $25 \%$ & $11 \%$ & $2 \%$ & $13 \%$ & $21 \%$ & $28 \%$ \\
\hline N & 678 & 344 & 334 & 407 & 269 & 490 & 177 & 454 & 221 & 126 & 552 & 106 & 321 & 134 & 57 \\
\hline
\end{tabular}

Fuente: datos de nuestra encuesta a docentes (abril-mayo 2020).

Si prestamos atención a atributos individuales nos encontramos con que estas condiciones materiales tampoco varían significativamente según género, aun cuando se evidencia un peso levemente superior de las mujeres en el grupo que no tiene ni computadora ni espacio aislado: 15\% de las mujeres versus el 10\% de los varones (Tabla I). Tomando en cuenta la configuración de los hogares en términos de la distribución interna de responsabilidades domésticas y de cuidado, observamos que casi un cuarto de los/as docentes con alta responsabilidad doméstica no tenía ni computadora ni espacio aislado, en tanto que solo un $10 \%$ de los/as docentes que tenían menores niveles de responsabilidad estaban en esa situación. En un sentido similar, un menor porcentaje de docentes con alta responsabilidad contaba con computadora y espacio: $39 \%$ en comparación con un $58 \%$ de sus colegas que no tenían altas responsabilidades en sus hogares. Cabe apuntar que son las mujeres las que tienen mayor carga de responsabilidades domésticas y de cuidado (Tabla I). Al considerar las características de los hogares, los/as docentes que pertenecían a unidades domésticas unipersonales tenían las mejores condiciones materiales relativas: un $76 \%$ contaba con computadora y con disponibilidad de espacio aislado. En cambio, las peores condiciones relativas (sin espacio aislado ni equipo) se concentraban en los hogares monoparentales con menores (28\%) y biparentales con menores $(21 \%$, Tabla I). 
Teletrabajo docente durante el confinamiento por COVID-19 en Argentina. Condiciones materiales y perspectivas sobre la carga de trabajo, la responsabilidad social y la toma de decisiones

La segunda condición material del trabajo docente en ASPO que analizaremos es el tiempo de trabajo. La percepción mayoritaria es que la jornada laboral se extendió durante la primera etapa del confinamiento. En el Tabla II observamos que cerca de 9 de cada 10 docentes dedican más tiempo a su trabajo ahora que antes del ASPO (aunque sea sólo «un poco más»). Los que afirman que les insume «mucho más tiempo que antes» son 3 de cada 4 encuestados/as. Los resultados de nuestro estudio sobre el inicio del ASPO convergen con las estimaciones hechas meses después por el Ministerio de Educación con niveles semejantes de ampliación de la jornada en Argentina (89\% de docentes de nivel secundario afirman que se ha incrementado la cantidad de trabajo en ASPO, ME-UNICEF, 2020).

El perfil social y sectorial de las escuelas incide en la ampliación de la jornada laboral: $83 \%$ de docentes de escuelas con alumnado de NSE medios y altos declara haber extendido mucho su tiempo de trabajo, frente al $69 \%$ de quienes se desempeñan en escuelas con alumnado de NSE bajo y medio-bajo. Un contraste aún mayor se registra entre sectores de gestión, pues la extensión de la jornada es más fuerte entre docentes del sector privado: $84 \%$ de ellos dedican mucho más tiempo que antes a la tarea docente (siendo $65 \%$ los de estatal) y solo $5 \%$ siente que trabaja igual o menos tiempo que antes del ASPO (frente a $16 \%$ en educación estatal, Tabla II). La ampliación de la jornada laboral de docentes de gestión privada ha sido constatada en estudios posteriormente realizados durante el ASPO (ME-UNICEF, 2020) y entendemos que se podría vincular, centralmente, al perfil socioeconómico de estudiantes ${ }^{3}$ (con mejores condiciones de vida y, por ende, más recursos TIC y mayor conectividad a Internet en sus hogares para afrontar la educación remota), y al efecto de las mayores expectativas y demandas familiares respecto del sostenimiento institucional de la escolaridad de sus hijos/as. Así, según los datos disponibles, en Argentina, el $21 \%$ de los/as estudiantes de escuelas secundarias privadas tiene problemas de conectividad (no tienen internet o no tiene acceso a datos en sus móviles) y/o no tiene computadora, en tanto que ese porcentaje asciende al $58 \%$ en las escuelas estatales (ME-UNICEF, 2020).

\section{Tabla II. Percepción de tiempo de trabajo en ASPO (en comparación con situación previa) según sector de gestión, NSE, género, nivel de responsabilidad doméstica y de cuidado, tenencia de plataforma en escuela y uso pedagógico de TIC en actividades con estudiantes antes del ASPO y tiempo dedicado a tareas domésticas en ASPO. Docentes de nivel secundario del Área Metropolitana, 2020}

\begin{tabular}{|c|c|c|c|c|c|c|c|c|c|c|c|c|c|c|}
\hline \multirow[b]{2}{*}{$\begin{array}{c}\text { CANTIDAD DE } \\
\text { TIEMPO DEDICADO AL } \\
\text { TRABAJO } \\
\text { DOCENTE EN ASPO }\end{array}$} & \multirow[b]{2}{*}{ 홍 } & \multicolumn{2}{|c|}{$\begin{array}{l}\text { SECTOR DE } \\
\text { GESTIÓN }\end{array}$} & \multicolumn{2}{|c|}{ NSE } & \multicolumn{2}{|c|}{ GÉNERO } & \multicolumn{2}{|c|}{$\begin{array}{c}\text { NIVEL DE } \\
\text { RESPONSABILIDAD } \\
\text { DOMÉSTICA Y DE CUIDADO }\end{array}$} & \multicolumn{2}{|c|}{$\begin{array}{l}\text { TENENCIA DE PLATAFORMA } \\
\text { Y USO PEDAGÓGICO DE TIC } \\
\text { ANTES DEL ASPO }\end{array}$} & \multicolumn{3}{|c|}{$\begin{array}{l}\text { TIEMPO DEDICADO } \\
\text { A TAREAS DOMÉSTICAS } \\
\text { EN ASPO }\end{array}$} \\
\hline & & 志 & 是 & 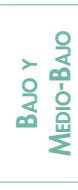 & 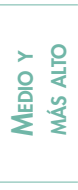 & 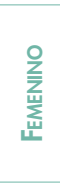 & 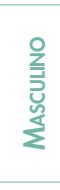 & 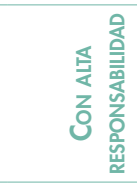 & 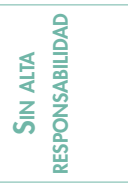 & 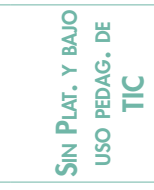 & 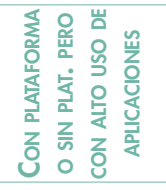 & 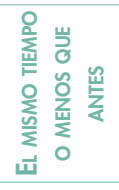 & 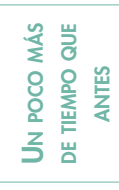 & 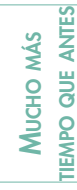 \\
\hline $\begin{array}{l}\text { Menos tiempo } \\
\text { que antes }\end{array}$ & $4 \%$ & $6 \%$ & $2 \%$ & $5 \%$ & $3 \%$ & $3 \%$ & $5 \%$ & $6 \%$ & $4 \%$ & $4 \%$ & $4 \%$ & $2 \%$ & $4 \%$ & $6 \%$ \\
\hline Mismas horas que antes & $7 \%$ & $10 \%$ & $3 \%$ & $9 \%$ & $3 \%$ & $6 \%$ & $8 \%$ & $6 \%$ & $7 \%$ & $8 \%$ & $7 \%$ & $7 \%$ & $7 \%$ & $7 \%$ \\
\hline Un poco más de tiempo & $15 \%$ & $19 \%$ & $10 \%$ & $17 \%$ & $12 \%$ & $13 \%$ & $21 \%$ & $14 \%$ & $15 \%$ & $17 \%$ & $14 \%$ & $13 \%$ & $16 \%$ & $16 \%$ \\
\hline Mucho más tiempo & $74 \%$ & $65 \%$ & $84 \%$ & $69 \%$ & $83 \%$ & $78 \%$ & $66 \%$ & $75 \%$ & $74 \%$ & $71 \%$ & $76 \%$ & $79 \%$ & $73 \%$ & $72 \%$ \\
\hline $\mathrm{N}$ & 678 & 344 & 334 & 407 & 269 & 490 & 177 & 126 & 552 & 252 & 401 & 197 & 261 & 215 \\
\hline
\end{tabular}

Fuente: datos de nuestra encuesta a docentes (abril-mayo 2020). 
$\mathrm{Al}$ analizar la relación entre sector de gestión de la escuela, perfil social del alumnado y jornada laboral en ASPO, se observa que la extensión del tiempo de trabajo es más fuerte en instituciones privadas de sectores medios y altos, donde un $87 \%$ dedica mucho más tiempo que antes. En el otro polo, si bien también la mayoría de los y las docentes de escuelas estatales de NSE bajo considera que incrementó «mucho» su jornada laboral, los valores son 26 pp. menores (61\%).

En cuanto a otras características institucionales, nuestra encuesta recaba información sobre la experiencia previa en uso pedagógico de TIC de las escuelas, así como la presencia de plataforma. En este caso, no se observa impacto sobre el incremento percibido en el tiempo de trabajo durante ASPO. Es posible hipotetizar que el carácter sorpresivo y contundente del cambio de condiciones de trabajo conllevó un aumento de la cantidad de horas dedicadas a reorganizar el trabajo para la gran mayoría de los/as docentes, más allá de las especificidades institucionales que ese reajuste o adaptación implicó.

Respecto de algunos atributos individuales, nuestra encuesta relevó la cantidad de escuelas donde trabajaban y cantidad de horas en la escuela principal ${ }^{4}$. Ninguna de estas características incide en la percepción de suba del tiempo de trabajo. En términos del género de los/as encuestados/as: las docentes mujeres tienen mayor percepción de que la jornada se ha extendido mucho más durante el confinamiento $(78 \%)$ que sus pares varones $(66 \%)$. Por su parte, la configuración familiar tampoco se asocia fuertemente con las percepciones sobre la extensión de la jornada, tanto al considerar si hay o no niños, niñas y adolescentes en el hogar, si hay miembros con mayor riesgo de COVID-19 (población de 60 y más años). En cambio, sí lo hace respecto de los niveles de responsabilidad en tareas domésticas y de cuidado. Así, observamos en la Tabla II una leve relación entre incremento en el tiempo laboral y descenso del tiempo dedicado a las tareas domésticas y de cuidado: $79 \%$ de quienes dedican igual, menos o ningún tiempo a las tareas domésticas en ASPO intensificaron su jornada laboral, siendo ese valor siete pp. menor entre quienes dedican mucho más tiempo que antes a las tareas hogareñas. Aparece así cierta compensación entre esferas de la vida social: quienes perciben que su jornada laboral docente se amplió «mucho» se concentran en hogares donde el cuidado de menores y las tareas domésticas les lleva menos tiempo que antes.

\section{La dimensión relacional del teletrabajo, carga laboral psíquica y mental, y respon- sabilidad social}

Para examinar cómo los/as docentes vivenciaron su teletrabajo forzado en sus hogares tendremos en cuenta tres aspectos: en primer lugar, cómo percibieron el proceso de toma de decisiones sobre aspectos centrales de su trabajo y el apoyo pedagógico y tecnológico en sus escuelas; en segundo lugar, cómo vivieron la virtualización forzada del trabajo prestando atención a la carga mental y psíquica del trabajo y, finalmente, cómo definen su responsabilidad social respecto de la acción educativa que se pudo desplegar para sostener las trayectorias educativas de sus estudiantes.

\subsection{Decisión y reflexión sobre la tarea y apoyos institucionales}

Las condiciones de trabajo en tiempos de excepcionalidad exigieron profundas alteraciones de modos de trabajo, de comunicación (entre docentes, docentes y autoridades, y con las familias) y de prioridades institucionales. En esta dimensión interesa analizar las relaciones que se forjaron entre docentes y

\footnotetext{
4 En todos los cuadros del trabajo no se presentan todas las variables independientes exploradas, sino aquellas que han mostrado asociación —aunque sea leve — con la variable dependiente en cuestión (en este caso, la percepción sobre el tiempo de trabajo en ASPO). Cuando las diferencias porcentuales son mínimas (menores a 5 pp.) entre categorías de la variable independiente, no se ha incorporado dicho cruce en la tabla resumen, puesto que su distribución es semejante a la del total.
} 
Teletrabajo docente durante el confinamiento por COVID-19 en Argentina. Condiciones materiales y perspectivas sobre la carga de trabajo, la responsabilidad social y la toma de decisiones

quienes orientaron aspectos centrales de su acción, tales como las autoridades escolares, coordinadores de área e incluso colegas.

El Gráfico 1 muestra que en la primera etapa del ASPO estas alteraciones fueron llevadas adelante sin promover formas colegiadas de toma de decisiones para definir aspectos claves de su trabajo (sólo el 20\% participó de decisiones colegiadas) ni recaer en los juicios profesionales de cada docente (sólo el 30\% afirmó que decidió individualmente cómo trabajar en ASPO). Por el contrario, más de un $75 \%$ de docentes afirmó que fue el equipo directivo el que tomó decisiones claves para organizar el trabajo docente durante la emergencia. Hubo otros actores que también fueron marginalizados de este proceso: el equipo de asesoría pedagógica (sólo el $20 \%$ afirmó que participó), el equipo de apoyo y orientación escolar (9\%), e incluso docentes coordinadores de área o departamentos (sólo el 36\%, Gráfico 1).

\section{Gráfico 1. Identificación de actores escolares que han participado en la definición de aspectos claves del trabajo docente en ASPO. Docentes de nivel secundario del Área Metropolitana de Buenos Aires (\% sobre casos totales)}

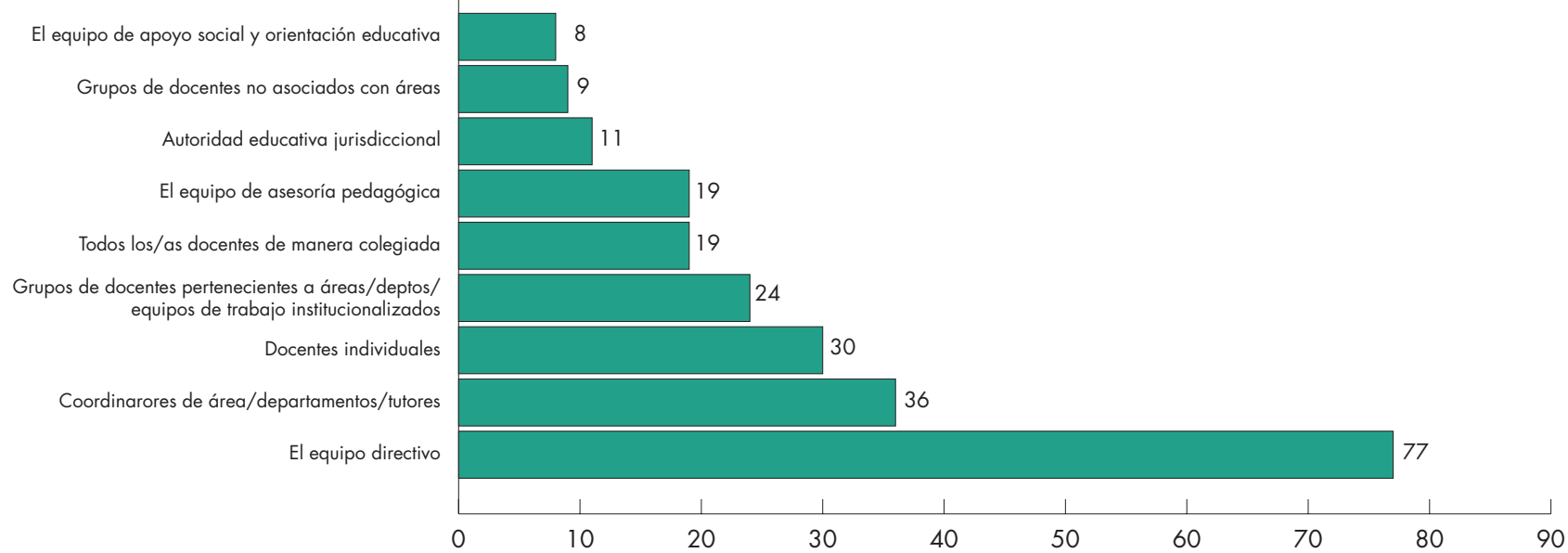

Fuente: datos de nuestra encuesta a docentes (abril-mayo 2020).

Diferentes estudios han mostrado cómo la presencia de una dirección colegiada es un aspecto significativo en la producción de condiciones favorables para la definición de escuelas eficaces e inclusivas (Spillane 2010). En nuestra encuesta indagamos la relación entre la presencia de decisiones colegiadas y el liderazgo de las autoridades escolares (Tabla III). Al hacerlo, observamos que solo el 15\% de los/as encuestados/as trabajaban en escuelas con esta modalidad mixta de gestión organizacional. Esta no sería una característica novedosa de nuestras escuelas, sino sedimentada en una larga tradición que ha asignado un lugar omnímodo a los equipos directivos y en el mismo movimiento ha tornado difícil la constitución de un «cuerpo» docente (Ezpeleta 1989).

Si analizamos esta situación por sector de gestión, se observa que solo un $11 \%$ de los/as docentes de escuelas estatales y un 19\% de privadas transitaron la emergencia en instituciones donde operaban liderazgos educativos y espacios colegiados para definir cursos de acción. En el mismo sentido, solo $13 \%$ de los/as docentes de escuelas de NSE bajo y medio bajo y un 18\% de los/as de NSE medio y alto habían participado de procesos colegiados de decisión y, al mismo tiempo, recibido lineamientos del equipo de conducción (Tabla III). 
Tabla III. Participación de equipo directivo por participación docente colegiada en la definición de aspectos claves del trabajo docente en ASPO por sector de gestión. Docentes de nivel secundario del Área Metropolitana de Buenos Aires (\% sobre totales)

\begin{tabular}{|c|c|c|c|c|c|}
\hline & \multicolumn{2}{|c|}{$\begin{array}{l}\text { PARTICIPACIÓN DOCENTE COLEGIADA } \\
\text { PARA DEFINIR SU TRABAJO }\end{array}$} & \multicolumn{3}{|c|}{$\begin{array}{l}\text { PARTICIPACIÓN DEL EQUIPO DIRECTIVO } \\
\text { EN DEFINIR SU TRABAJO DOCENTE }\end{array}$} \\
\hline & & & No & Si & TOTAL \\
\hline \multirow{2}{*}{ Estatal } & № & \% del Total & $25 \%$ & $59 \%$ & $84 \%$ \\
\hline & Sí & \% del Total & $5 \%$ & $11 \%$ & $16 \%$ \\
\hline \multirow{2}{*}{ Total Estatal } & & $\mathrm{N}$ & 102 & 242 & 344 \\
\hline & & \% del Total & $30 \%$ & $70 \%$ & $100 \%$ \\
\hline \multirow[b]{2}{*}{ Privado } & No & \% del Total & $12 \%$ & $66 \%$ & $77 \%$ \\
\hline & Sí & \% del Total & $4 \%$ & $19 \%$ & $23 \%$ \\
\hline \multirow{2}{*}{ Total Privado } & & $\mathrm{N}$ & 51 & 283 & 334 \\
\hline & & \% del Total & $15 \%$ & $85 \%$ & $100 \%$ \\
\hline \multirow{2}{*}{ Total } & No & \% del Total & $18 \%$ & $62 \%$ & $81 \%$ \\
\hline & Si & \% del Total & $4 \%$ & $15 \%$ & $19 \%$ \\
\hline \multirow{2}{*}{ Total } & & $\mathrm{N}$ & 153 & 525 & 678 \\
\hline & & \% del Total & $23 \%$ & $77 \%$ & $100 \%$ \\
\hline
\end{tabular}

Fuente: datos de nuestra encuesta a docentes (abril-mayo 2020).

Otros aspectos constitutivos de la dimensión relacional refieren a los vínculos que los/as docentes establecieron entre sí y con el equipo de conducción para llevar adelante su teletrabajo e ir revisando sus acciones educativas. Más de la mitad de los/as docentes afirmó que se dificultó la reflexión sobre las prácticas y el intercambio con colegas durante el ASPO (52\%) (Tabla IV). Esta dificultad de reflexión e intercambio resultó más frecuente entre docentes en escuelas con bajo uso de TIC antes del confinamiento $(57 \%)$ y de gestión estatal (59\%). Las respuestas abiertas de nuestra encuesta hacen referencia a ritmos de demanda «frenéticos», «abrumadores» y, como vimos en el apartado anterior, a la ampliación de la jornada e intensificación del trabajo (Meo, 2020). En estas condiciones no parece sorprendente que la mayoría de los/as docentes no tuviera tiempos ni espacio mental (como veremos en apartado siguiente) para objetivar y revisar sus prácticas con otros/as.

Tabla IV. Grado de acuerdo con la frase «Durante el ASPO, se ha dificultado la reflexión sobre las prácticas y el intercambio con los colegas» según sector de gestión de escuela, NSE de alumnado y recursos TIC en escuela antes del ASPO. Docentes de nivel secundario del Área Metropolitana de Buenos Aires (\%)

\begin{tabular}{|c|c|c|c|c|c|c|c|}
\hline \multirow[b]{2}{*}{$\begin{array}{l}\text { DIFICULTAD EN } \\
\text { REFLEXIÓN SOBRE } \\
\text { PRÁCTICAS Y ENTRE } \\
\text { COLEGAS }\end{array}$} & \multirow[b]{2}{*}{ TOTAL } & \multicolumn{2}{|c|}{ SECTOR DE GESTIÓN } & \multicolumn{2}{|c|}{ NSE } & \multicolumn{2}{|c|}{$\begin{array}{l}\text { TENENCIA DE PLATAFORMA Y USO } \\
\text { PEDAGÓGICO DE TIC EN ACTIVIDADES } \\
\text { CON ESTUDIANTES ANTES DEL ASPO }\end{array}$} \\
\hline & & EstatAl. & PrIVAdo & Bajo y Medio-Bajo & MEdio y más ALto & $\begin{array}{l}\text { SIN PLAT. y BAJO USO } \\
\text { PEDAG. DE TIC }\end{array}$ & $\begin{array}{l}\text { CON PLATAFORMA O SIN } \\
\text { PLAT. PERO CON ALTO USO } \\
\text { DE APLICACIONES }\end{array}$ \\
\hline Nada de acuerdo & $17 \%$ & $10 \%$ & $24 \%$ & $14 \%$ & $22 \%$ & $13 \%$ & $19 \%$ \\
\hline Poco de acuerdo & $31 \%$ & $30 \%$ & $32 \%$ & $30 \%$ & $33 \%$ & $30 \%$ & $32 \%$ \\
\hline Bastante de acuerdo & $32 \%$ & $35 \%$ & $29 \%$ & $34 \%$ & $29 \%$ & $28 \%$ & $35 \%$ \\
\hline Muy de acuerdo & $20 \%$ & $24 \%$ & $15 \%$ & $22 \%$ & $16 \%$ & $29 \%$ & $13 \%$ \\
\hline $\mathrm{N}$ & 678 & 344 & 334 & 407 & 269 & 252 & 401 \\
\hline
\end{tabular}

Fuente: datos de nuestra encuesta a docentes (abril-mayo 2020). 
Teletrabajo docente durante el confinamiento por COVID-19 en Argentina. Condiciones materiales y perspectivas sobre la carga de trabajo, la responsabilidad social y la toma de decisiones

En cuanto al sostén institucional de su tarea (Gráfico 2), sólo algo más de la mitad de los/as docentes afirmó haber sido «frecuentemente» $\mathrm{O}$ «muy frecuentemente» acompañado tecnológica y pedagógicamente por pares y/o coordinadores (un 54\%) y otro tanto por el equipo de conducción (53\%). Mientras que alrededor de un tercio sintió que fue acompañado/a solo «pocas»o «algunas veces»y uno de cada diez encuestados/as sintió que nunca fue acompañado/a por la dirección escolar o por colegas en sus estrategias pedagógicas y/o procesos de aprendizajes de nuevos recursos tecnológicos.

\section{Gráfico 2. Frecuencia de acompañamiento tecnológico y pedagógico de parte de equipos directivos y otros por docentes y/o coordinadores. Docentes de nivel secundario del Área Metropolitana de Buenos Aires (\%)}

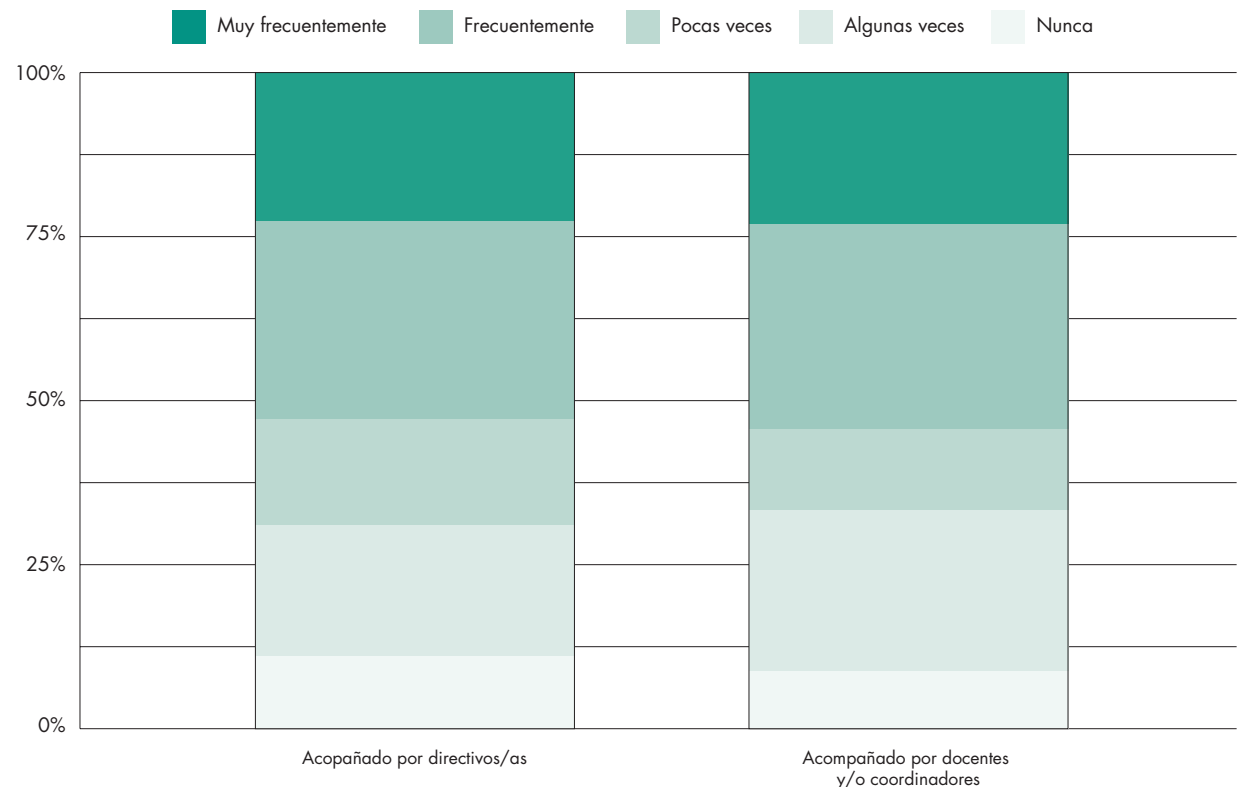

Fuente: elaboración propia en base a nuestra encuesta a docentes (abril-mayo 2020).

La frecuencia de acompañamiento tecnológico y pedagógico del equipo de conducción se vinculaba con tres atributos institucionales. Por un lado, $66 \%$ de los/as docentes en escuelas con tradición previa de uso de TIC recibieron apoyo «frecuentemente» y «muy frecuentemente», en tanto sólo el 34\% lo había recibido así en las escuelas con bajo uso de TIC previo al ASPO. También incidía el sector de gestión puesto que seis de cada 10 docentes de escuelas privadas se sintieron acompañados «frecuentemente» $\mathrm{y}$ «muy frecuentemente» $(63 \%)$, frente a solo $44 \%$ entre docentes del sector estatal. Finalmente, hay una asociación más leve entre el nivel socioeconómico del alumnado y la vivencia de haber sido «muy frecuentemente» acompañado: tres de cada 10 docentes en escuelas con NSE medio y alto versus dos de cada 10 en escuelas con NSE bajo y medio-bajo.

En caso del acompañamiento de sus colegas, encontramos las asociaciones con el sector de gestión de la escuela y el NSE del estudiantado son más leves (con diferencias de 10 pp.) a favor de las escuelas privadas y las de NSE más alto para quienes se sintieron acompañados «frecuentemente» $\mathrm{y}$ 《muy frecuentemente» (60\% en escuelas privadas y $50 \%$ en estatales y $50 \%$ en escuelas con NSE bajo y medio bajo y $59 \%$ en las de NSE superior). Asimismo, quienes trabajaron en una sola escuela se sintieron acompañados «frecuentemente» $\mathrm{y}$ «muy frecuentemente» por colegas $(61 \%)$ en mayores proporciones que los que trabajaban en dos escuelas $(56 \%)$ y es significativamente menor para los que trabajan en tres y más escuelas $(47 \%)$. 


\subsection{Carga mental y psíquica del trabajo}

Nuestra encuesta exploró la percepción de estar desbordados por el teletrabajo en el inicio del ASPO por tener que virtualizar tareas con colegas y por la virtualización de acciones pedagógicas. Observamos en la Tabla $\mathrm{V}$ que la mitad de los/as docentes respondieron que «frecuente» y «muy frecuentemente» se sentían desbordados por el trabajo adicional que suponía intercambiar virtualmente con colegas. El sector de gestión de la escuela está asociado con la frecuencia de sentirse desbordados, puesto que $55 \%$ del sector privado se sentían así «frecuente» y «muy frecuentemente», mientras estaba en esa condición solo $43 \%$ del sector estatal. También este sentimiento de estar superado/a por las demandas de trabajar con otros/as virtualmente se asocia con el NSE de los/as estudiantes: así el $43 \%$ de los/as docentes que trabajan con población de NSE bajo y medio-bajo y el 57\% de los que lo hacen con NSE medio y alto.

Tabla V. Nivel de frecuencia de vivencia «Me siento desbordado/a por la carga de trabajo adicional derivada de la necesidad de trabajar virtualmente con colegas» según sector de gestión de escuela, NSE de alumnado, género y cantidad de escuelas donde trabaja. Docentes de nivel secundario del Área Metropolitana de Buenos Aires (\%)

\begin{tabular}{|c|c|c|c|c|c|c|c|c|c|c|}
\hline & & \multicolumn{2}{|c|}{$\begin{array}{c}\text { SECTOR } \\
\text { DE GESTIÓN }\end{array}$} & \multicolumn{2}{|c|}{ NSE } & \multicolumn{2}{|c|}{ GÉNERO } & \multicolumn{3}{|c|}{$\begin{array}{l}\text { CANT. ESCUELAS } \\
\text { DONDE TRABAJA }\end{array}$} \\
\hline $\begin{array}{c}\text { DESBORDE POR } \\
\text { CARGA ADICIONAL } \\
\text { DE TRABAJO VIRTUAL } \\
\text { CON COLEGAS }\end{array}$ & TOTAL & ESTATAL & PrIVAdo & $\begin{array}{c}\text { Bajo Y } \\
\text { Medio-Bajo }\end{array}$ & $\begin{array}{c}\text { Medio y mÁs } \\
\text { ALto }\end{array}$ & FemenINo & MAsculino & $\begin{array}{c}\text { UNA } \\
\text { EsCUELA }\end{array}$ & $\begin{array}{c}\text { Dos } \\
\text { ESCUELAS }\end{array}$ & $\begin{array}{c}\text { TRES } \\
\text { ESCUELAS O + }\end{array}$ \\
\hline Nunca & $14 \%$ & $16 \%$ & $12 \%$ & $15 \%$ & $12 \%$ & $13 \%$ & $17 \%$ & $16 \%$ & $12 \%$ & $14 \%$ \\
\hline Algunas veces & $21 \%$ & $22 \%$ & $20 \%$ & $22 \%$ & $19 \%$ & $21 \%$ & $20 \%$ & $23 \%$ & $19 \%$ & $20 \%$ \\
\hline Pocas veces & $16 \%$ & $19 \%$ & $13 \%$ & $19 \%$ & $12 \%$ & $15 \%$ & $19 \%$ & $18 \%$ & $14 \%$ & $16 \%$ \\
\hline Frecuentemente & $22 \%$ & $21 \%$ & $24 \%$ & $20 \%$ & $26 \%$ & $22 \%$ & $23 \%$ & $19 \%$ & $25 \%$ & $22 \%$ \\
\hline Muy frecuentemente & $26 \%$ & $22 \%$ & $31 \%$ & $23 \%$ & $30 \%$ & $29 \%$ & $20 \%$ & $22 \%$ & $29 \%$ & $27 \%$ \\
\hline Sin dato & $1 \%$ & $1 \%$ & $1 \%$ & $1 \%$ & $1 \%$ & $1 \%$ & $1 \%$ & $1 \%$ & $1 \%$ & $1 \%$ \\
\hline N & 678 & 344 & 334 & 407 & 269 & 490 & 177 & 196 & 230 & 252 \\
\hline
\end{tabular}

Fuente: datos de nuestra encuesta a docentes (abril-mayo 2020).

Respecto de los atributos individuales, observamos una leve asociación con el género en el grupo que «muy frecuentemente» no podía responder a la exigencia de trabajo virtual ( $29 \%$ de mujeres versus $20 \%$ de varones). También se aprecia asociación entre cantidad de escuelas en la que trabajaban y la mayor carga mental y psíquica derivada del trabajo colegiado virtual: $41 \%$ de los/as docentes que trabajan en una escuela versus el $53 \%$ de los que lo hacían en 2 , y el $49 \%$ de quienes que lo hacían en tres escuelas o más (Tabla V) .

En segundo lugar, ante la frase «Me siento desbordado/a por la carga de trabajo adicional derivada de la virtualización de mis clases» casi 6 de cada 10 docentes (54\%) identificaron haber estado «frecuente» $\mathrm{y}$ «muy frecuentemente» (Tabla VI). La mayor carga mental y psíquica se registraba en la educación privada: $63 \%$ denotaba sobrecarga, cifra que era $52 \%$ en la educación estatal. Lo mismo sucede con el NSE del estudiantado, con mayor sobrecarga (65\%) de los que trabajaban con NSE medio y medio-alto ( $65 \%$, valor que era solo del $51 \%$ en escuelas con población NSE bajo y medio-

5 En el total de la muestra de nuestra encuesta tienen pluriempleo el $61 \%$ de los/as encuestados y cerca de cuatro de cada 10 trabaja en tres escuelas o más. 
-bajo). En cuanto a los atributos individuales, se observa una asociación entre sentirse desbordado por la exigencia de virtualizar las acciones educativas con el nivel de responsabilidad en el hogar: 65\% de docentes con alta responsabilidad tenían una alta carga psíquica y mental, frente al 53\% de los que no la tenían en sus hogares. En cuanto a la percepción de la extensión de la jornada laboral, encontramos un hallazgo llamativo: un $73 \%$ de los que dedicaron menos tiempo declaraba alta carga psíquica versus el 54\% de los que le dedicaron mucho más tiempo. Se puede conjeturar que esto tendría que ver con que la intensificación de carga psíquica tiene que ver con el tipo de tareas desempeñadas, antes que con la cantidad de horas dedicadas a ellas. Se necesitará indagar más si esto fue efectivamente así. Asimismo, identificamos que esta carga psíquica es mayor en docentes que trabajan en más cantidad de escuelas: se sienten «muy frecuentemente» un $52 \%$ de docentes que trabaja en una escuela versus un $60 \%$ de los/as que trabajaban en dos escuelas y más (Tabla VI).

\section{Tabla VI. Nivel de frecuencia de vivencia «Me siento desbordado/a por la carga de trabajo adicional derivada de la virtualización de mis clases» según sector de gestión de escuela, NSE de alumnado, responsabilidades domésticas y de cuidado y cantidad de escuelas donde trabaja. Docentes de nivel secundario del Área Metropolitana de Buenos Aires (\%)}

\begin{tabular}{|c|c|c|c|c|c|c|c|c|c|}
\hline \multirow[b]{2}{*}{$\begin{array}{c}\text { DESBORDE POR CARGA } \\
\text { ADICIONAL DE VIRTUALIZACIÓN } \\
\text { DE LAS CLASES }\end{array}$} & \multirow[b]{2}{*}{ TOTAL } & \multicolumn{2}{|c|}{$\begin{array}{c}\text { SECTOR } \\
\text { DE GESTIÓN }\end{array}$} & \multicolumn{2}{|c|}{ NSE } & \multicolumn{2}{|c|}{$\begin{array}{l}\text { RESPONSABILIDADES } \\
\text { DOMÉSTICAS Y DE } \\
\text { CUIDADO }\end{array}$} & \multicolumn{2}{|c|}{$\begin{array}{l}\text { CANT. ESCUELAS } \\
\text { DONDE TRABAJA }\end{array}$} \\
\hline & & EstatAl & Privado & $\begin{array}{c}\text { Bajo Y } \\
\text { MEdIO-Bajo }\end{array}$ & $\begin{array}{c}\text { MeDIO } \\
\text { Y MÁs ALTO }\end{array}$ & Alta & No ALTA & $\begin{array}{c}\text { UNA } \\
\text { EsCUELA }\end{array}$ & $\begin{array}{c}\text { Dos } \\
\text { ESCUELAS Y + }\end{array}$ \\
\hline Nunca & $8 \%$ & $11 \%$ & $5 \%$ & $10 \%$ & $6 \%$ & $4 \%$ & $9 \%$ & $10 \%$ & $7 \%$ \\
\hline Algunas veces & $22 \%$ & $22 \%$ & $21 \%$ & $23 \%$ & $19 \%$ & $24 \%$ & $21 \%$ & $24 \%$ & $21 \%$ \\
\hline Pocas veces & $12 \%$ & $14 \%$ & $10 \%$ & $14 \%$ & $9 \%$ & $7 \%$ & $13 \%$ & $12 \%$ & $12 \%$ \\
\hline Frecuentemente & $23 \%$ & $24 \%$ & $22 \%$ & $22 \%$ & $24 \%$ & $28 \%$ & $22 \%$ & $25 \%$ & $22 \%$ \\
\hline Muy frecuentemente & $34 \%$ & $28 \%$ & $41 \%$ & $30 \%$ & $42 \%$ & $37 \%$ & $34 \%$ & $27 \%$ & $37 \%$ \\
\hline Sin dato & $1 \%$ & $1 \%$ & $1 \%$ & $1 \%$ & $1 \%$ & $0 \%$ & $1 \%$ & $1 \%$ & $1 \%$ \\
\hline $\mathrm{N}$ & 678 & 344 & 334 & 407 & 269 & 126 & 552 & 196 & 482 \\
\hline
\end{tabular}

Fuente: datos de nuestra encuesta a docentes (abril-mayo 2020).

Otra pregunta incluida en la encuesta para mapear el nivel de carga psíquica negativa promovida por decisiones institucionales fue el grado de acuerdo con la frase «Estamos muy presionados/as en esta escuela para virtualizar nuestro trabajo sin contar con herramientas ni capacitación para hacerlo» (Tabla VII). Casi la mitad de los/as encuestados/as estaban de acuerdo con esta afirmación. Esta percepción está asociada negativamente con el uso previo de TIC en las escuelas: $44 \%$ de los/as que trabajaban en escuelas con uso más intensivo previo estaban de acuerdo, versus el $55 \%$ de escuelas con bajo uso de TIC. Si observamos al grupo que estaba «muy de acuerdo» con esta frase, la asociación es aún más fuerte: $26 \%$ en escuelas con bajo uso previo TIC versus $17 \%$ en instituciones con uso más intensivo. En cuanto al sector de gestión, es interesante observar que son los/as docentes del sector estatal quienes se sintieron más presionados/as que sus pares en el privado: $53 \%$ versus 43 respectivamente afirmaron que estaban de acuerdo y muy de acuerdo con la frase que le presentamos. En cambio, no se identifica asociación entre este tipo de carga psíquica y el NSE de los/as estudiantes (Tabla VII). 
Tabla VII. Nivel de frecuencia de vivencia "Estamos muy presionados/as en esta escuela para virtualizar nuestro trabajo sin contar con herramientas ni capacitación para hacerlo» según sector de gestión de escuela, NSE de alumnado y alumnado y tenencia de plataforma y uso pedagógico de TIC antes del ASPO. Docentes de nivel secundario del Área Metropolitana de Buenos Aires (\%)

\begin{tabular}{|c|c|c|c|c|c|c|c|}
\hline \multirow[b]{2}{*}{$\begin{array}{l}\text { PRESIÓN POR VIRTUALIZAR SIN } \\
\text { HERRAMIENTAS NI } \\
\text { CAPACITACIÓN }\end{array}$} & \multirow[b]{2}{*}{ TOTAL } & \multicolumn{2}{|c|}{$\begin{array}{c}\text { SECTOR } \\
\text { DE GESTIÓN }\end{array}$} & \multicolumn{2}{|c|}{ NSE } & \multicolumn{2}{|c|}{$\begin{array}{c}\text { TENENCIA DE PLATAFORMA Y USO PEDAGÓGICO } \\
\text { DE TIC EN ACTIVIDADES CON ESTUDIANTES } \\
\text { ANTES DEL ASPO }\end{array}$} \\
\hline & & EstATAL. & PrIVADO & $\begin{array}{c}\text { Bajo Y } \\
\text { MEDIO-BAJO }\end{array}$ & $\begin{array}{c}\text { MEDIO } \\
\text { Y MÁs ALTO }\end{array}$ & $\begin{array}{c}\text { SIN PLAT. } \\
\text { Y BAJO USO PEDAG. DE TIC }\end{array}$ & $\begin{array}{l}\text { CON PLATAFORMA O SIN PLAT. } \\
\text { PERO CON ALTO USO } \\
\text { DE APLICACIONES }\end{array}$ \\
\hline Nada de acuerdo & $22 \%$ & $18 \%$ & $25 \%$ & $20 \%$ & $25 \%$ & $15 \%$ & $25 \%$ \\
\hline Poco de acuerdo & $31 \%$ & $29 \%$ & $32 \%$ & $30 \%$ & $31 \%$ & $30 \%$ & $31 \%$ \\
\hline Bastante de acuerdo & $28 \%$ & $30 \%$ & $25 \%$ & $28 \%$ & $27 \%$ & $29 \%$ & $27 \%$ \\
\hline Muy de acuerdo & $20 \%$ & $22 \%$ & $18 \%$ & $22 \%$ & $17 \%$ & $26 \%$ & $16 \%$ \\
\hline $\mathrm{N}$ & 678 & 344 & 334 & 407 & 269 & 252 & 401 \\
\hline
\end{tabular}

Fuente: datos de nuestra encuesta a docentes (abril-mayo 2020).

Un último indicador que tomaremos de carga psíquica y mental es el grado de acuerdo con la pregunta «He descubierto potencialidades en el trabajo online que hasta ahora me eran desconocidas». Seis de cada 10 docentes estaban bastante o muy de acuerdo con esta frase. Para estos casos, la situación de aprendizaje de nuevas herramientas (impuesta por la virtualización de emergencia de la acción pedagógica) era interpretada positivamente (Tabla VIII).

Tabla VIII. Grado de acuerdo con la frase «He descubierto potencialidades en el trabajo online que hasta ahora me eran desconocidas» según sector de gestión de escuela,

NSE de alumnado, género y tenencia de plataforma y uso pedagógico de TIC antes del ASPO. Docentes de nivel secundario del Área Metropolitana de Buenos Aires (\%)

\begin{tabular}{|c|c|c|c|c|c|c|c|c|c|}
\hline \multirow[b]{2}{*}{$\begin{array}{l}\text { POTENCIALIDADES } \\
\text { DEL TRABAJO ONLINE }\end{array}$} & \multirow[b]{2}{*}{ TOTAL } & \multicolumn{2}{|c|}{$\begin{array}{c}\text { SECTOR } \\
\text { DE GESTIÓN }\end{array}$} & \multicolumn{2}{|c|}{ NSE } & \multicolumn{2}{|c|}{ GÉNERO } & \multicolumn{2}{|c|}{$\begin{array}{l}\text { TENENCIA DE PLATAFORMA Y USO } \\
\text { PEDAGÓGICO DE TIC EN ACTIVIDADES } \\
\text { CON ESTUDIANTES ANTES DEL ASPO }\end{array}$} \\
\hline & & EstatAl & PrIVADO & $\begin{array}{c}\text { Bajo Y } \\
\text { Medio-Bajo }\end{array}$ & $\begin{array}{c}\text { MEDIO } \\
\text { Y MÁs ALTO }\end{array}$ & Femenino & MASCULINO & $\begin{array}{l}\text { Sin Plat. } \\
\text { Y BAJO USO PEDAG. DE TIC }\end{array}$ & $\begin{array}{l}\text { CON PLATAFORMA O SIN } \\
\text { PLAT. PERO CON ALTO USO } \\
\text { DE APLICACIONES }\end{array}$ \\
\hline Nada de acuerdo & $12 \%$ & $16 \%$ & $8 \%$ & $14 \%$ & $10 \%$ & $12 \%$ & $13 \%$ & $15 \%$ & $8 \%$ \\
\hline Poco de acuerdo & $27 \%$ & $31 \%$ & $23 \%$ & $28 \%$ & $26 \%$ & $27 \%$ & $28 \%$ & $30 \%$ & $26 \%$ \\
\hline Bastante de acuerdo & $35 \%$ & $34 \%$ & $37 \%$ & $36 \%$ & $35 \%$ & $33 \%$ & $42 \%$ & $35 \%$ & $36 \%$ \\
\hline Muy de acuerdo & $25 \%$ & $18 \%$ & $32 \%$ & $22 \%$ & $30 \%$ & $28 \%$ & $17 \%$ & $19 \%$ & $29 \%$ \\
\hline $\mathrm{N}$ & 678 & 344 & 334 & 407 & 269 & 490 & 177 & 252 & 401 \\
\hline
\end{tabular}

Fuente: datos de nuestra encuesta a docentes (abril-mayo 2020).

En las escuelas con mayor uso de TIC previo al ASPO, del sector privado y para población de NSE medio y medio-alto se observa un peso mayor de los/as docentes/as que estaban «muy de acuerdo» con esa frase (29\% en escuela con más intensivo uso de TIC versus $19 \%$ con bajo uso; $32 \%$ en escuelas estatales versus $18 \%$ en privadas; $30 \%$ versus $22 \%$ con estudiantes de NSE bajo y medio-bajo). Es interesante mencionar que se da una asociación más leve entre género y esta valoración de la posibilidad de aprendizaje en tiempos de fuertes cambios: casi tres de cada diez mujeres (28\%) están «muy de acuerdo» con la idea del descubrimiento de potencialidades, en tanto casi dos varones están en esa 
Teletrabajo docente durante el confinamiento por COVID-19 en Argentina. Condiciones materiales y perspectivas sobre la carga de trabajo, la responsabilidad social y la toma de decisiones

situación (17\%). Por otro lado, cuatro de cada 10 estaban poco o nada de acuerdo con esa frase (Tabla VIII). Podríamos interpretar que para estos docentes la necesidad de aprender nuevas herramientas y recursos digitales era visto como un mal necesario antes que como una oportunidad.

\subsection{Responsabilidad social respecto de acciones educativas}

La «responsabilidad social» atribuida a la tarea docente es un aspecto de la carga psíquica del trabajo y resulta, a la vez, un elemento constitutivo de su identidad profesional ligado al reconocimiento social. $\mathrm{Al}$ respecto, recuperamos sobre este punto tres indicadores de nuestra encuesta. En primer lugar, las preocupaciones profesionales en torno al impacto negativo del confinamiento en el aumento de la deserción escolar. En segundo término, la frustración y falta de sentido que generaría el hecho de que no hayan logrado establecer comunicación con sus estudiantes. Tercero, la responsabilidad profesional de sostener el vínculo pedagógico como modo de concreción de las políticas de continuidad pedagógicas instaladas desde las órbitas ministeriales.

\section{Tabla IX. Frecuencia de preocupación por efectos ASPO en deserción escolar según sector de gestión, NSE, recursos TIC en su escuela pre-ASPO y cantidad de escuelas donde trabaja. Docentes de nivel secundario del Área Metropolitana, 2020}

\begin{tabular}{|c|c|c|c|c|c|c|c|c|c|}
\hline \multirow[b]{2}{*}{$\begin{array}{l}\text { PREOCUPACIÓN POR } \\
\text { EFECTOS DEL ASPO EN } \\
\text { DESERCIÓN ESCOLAR }\end{array}$} & \multirow[b]{2}{*}{ TOTAL } & \multicolumn{2}{|c|}{$\begin{array}{c}\text { SECTOR } \\
\text { DE GESTIÓN }\end{array}$} & \multicolumn{2}{|c|}{ NSE } & \multicolumn{2}{|c|}{$\begin{array}{l}\text { TENENCIA DE PLATAFORMA Y USO } \\
\text { PEDAGÓGICO DE TIC EN ACTIVIDADES } \\
\text { CON ESTUDIANTES ANTES DEL ASPO }\end{array}$} & \multicolumn{2}{|c|}{$\begin{array}{l}\text { CANTIDAD } \\
\text { DE ESCUELAS } \\
\text { DONDE TRABAJA }\end{array}$} \\
\hline & & EstatAl & Privado & $\begin{array}{c}\text { Bajo Y } \\
\text { MedIO-BAJO }\end{array}$ & $\begin{array}{c}\text { MEDIO } \\
\text { Y MÁs ALTO }\end{array}$ & $\begin{array}{l}\text { SIN PLAT. } \\
\text { Y BAJO USO PEDAG. DE TIC }\end{array}$ & $\begin{array}{l}\text { CON PLATAFORMA O SIN } \\
\text { PLAT. PERO CON ALTO USO } \\
\text { DE APLICACIONES }\end{array}$ & $1 \circ 2$ & $3 y+s$ \\
\hline Nunca & $19 \%$ & $14 \%$ & $24 \%$ & $14 \%$ & $26 \%$ & $17 \%$ & $20 \%$ & $22 \%$ & $14 \%$ \\
\hline Algunas veces & $19 \%$ & $19 \%$ & $19 \%$ & $17 \%$ & $22 \%$ & $22 \%$ & $17 \%$ & $19 \%$ & $21 \%$ \\
\hline Pocas veces & $14 \%$ & $10 \%$ & $19 \%$ & $12 \%$ & $18 \%$ & $10 \%$ & $18 \%$ & $17 \%$ & $10 \%$ \\
\hline Frecuentemente & $22 \%$ & $24 \%$ & $19 \%$ & $25 \%$ & $17 \%$ & $24 \%$ & $20 \%$ & $19 \%$ & $27 \%$ \\
\hline Muy frecuentemente & $24 \%$ & $32 \%$ & $17 \%$ & $30 \%$ & $16 \%$ & $27 \%$ & $22 \%$ & $23 \%$ & $23 \%$ \\
\hline $\mathrm{N}$ & 678 & 344 & 334 & 399 & 265 & 250 & 392 & 421 & 240 \\
\hline
\end{tabular}

Fuente: datos de nuestra encuesta a docentes (abril-mayo 2020).

Cerca de la mitad de los y las docentes anticipan «frecuente» y «muy frecuentemente» efectos negativos de la educación no presencial sobre la deserción (46\%). De las cuatro variables con mayor incidencia en este indicador el sector de gestión y NSE de la escuela son las de mayor impacto (Tabla IX). Más de la mitad de los/as docentes de educación estatal frecuente y muy frecuentemente piensan que el confinamiento intensificará el abandono escolar, mientras esas preocupaciones afectan solo a un tercio de los de educación privada (36\%). En el mismo sentido, la deserción es una preocupación poco frecuente entre docentes de escuelas con alumnado de NSE medios o superiores (32\%), pero mayoritarias en las de NSE más bajos (55\%). Los efectos negativos en la continuidad escolar son percibidos en mayor medida entre docentes de escuelas con escasa tradición de uso pedagógico de TIC antes del ASPO (51\%, 9 pp. más que en escuelas con mayor tradición en uso de TIC) y entre quienes trabajan en muchas escuelas ( $55 \%$ entre los que trabajan en más de tres escuelas y $42 \%$ entre los que trabajan solo en una o dos). En cambio, es mínima la incidencia de factores individuales como el género o la cantidad de horas de trabajo en su escuela principal y las configuraciones familiares analizadas en el artículo (Tabla IX). 
Teletrabajo docente durante el confinamiento por COVID-19 en Argentina. Condiciones materiales y perspectivas sobre la carga de trabajo, la responsabilidad social y la toma de decisiones

Tabla X. Grado de acuerdo con la frase «Solo hemos podido comunicarnos con una minoría de los/as alumnos/as» según sector de gestión, NSE, recursos TIC en su escuela pre-ASPO y cantidad de escuelas donde trabaja. Docentes de nivel secundario del Área Metropolitana, 2020

\begin{tabular}{|c|c|c|c|c|c|c|c|c|c|}
\hline \multirow[b]{2}{*}{$\begin{array}{l}\text { COMUNICACIÓN CON } \\
\text { UNA MINORÍA DE } \\
\text { ALUMNOS/AS }\end{array}$} & \multirow[b]{2}{*}{ TOTAL } & \multicolumn{2}{|c|}{$\begin{array}{c}\text { SECTOR } \\
\text { DE GESTIÓN }\end{array}$} & \multicolumn{2}{|c|}{ NSE } & \multicolumn{2}{|c|}{$\begin{array}{l}\text { TENENCIA DE PLATAFORMA Y USO } \\
\text { PEDAGÓGICO DE TIC EN ACTIVIDADES } \\
\text { CON ESTUDIANTES ANTES DEL ASPO }\end{array}$} & \multicolumn{2}{|c|}{$\begin{array}{l}\text { CANTIDAD } \\
\text { DE ESCUELAS } \\
\text { DONDE TRABAJA }\end{array}$} \\
\hline & & EstatAl & PrIVADO & $\begin{array}{c}\text { Bajo Y } \\
\text { MedIO-BAJO }\end{array}$ & $\begin{array}{c}\text { MEDIO } \\
\text { y MÁs ALTO }\end{array}$ & $\begin{array}{l}\text { Sin Plat. } \\
\text { Y BAJO USO PEDAG. DE TIC }\end{array}$ & $\begin{array}{l}\text { CON PLATAFORMA O SIN } \\
\text { PLAT. PERO CON ALTO USO } \\
\text { DE APLICACIONES }\end{array}$ & $1 \circ 2$ & $3 Y+$ \\
\hline Nada de acuerdo & $36 \%$ & $19 \%$ & $52 \%$ & $24 \%$ & $54 \%$ & $28 \%$ & $41 \%$ & $39 \%$ & $30 \%$ \\
\hline Poco de acuerdo & $30 \%$ & $31 \%$ & $29 \%$ & $31 \%$ & $29 \%$ & $31 \%$ & $31 \%$ & $32 \%$ & $28 \%$ \\
\hline Bastante de acuerdo & $21 \%$ & $29 \%$ & $13 \%$ & $27 \%$ & $13 \%$ & $23 \%$ & $19 \%$ & $18 \%$ & $26 \%$ \\
\hline Muy de acuerdo & $13 \%$ & $20 \%$ & $5 \%$ & $18 \%$ & $4 \%$ & $18 \%$ & $9 \%$ & $11 \%$ & $16 \%$ \\
\hline N & 678 & 344 & 334 & 407 & 269 & 252 & 401 & 426 & 247 \\
\hline
\end{tabular}

Fuente: datos de nuestra encuesta a docentes (abril-mayo 2020).

La comunicación con estudiantes es condición de posibilidad del reconocimiento social de su función y fue posible en la mayoría de los casos: solo un 13\% estaba «muy de acuerdo» con la frase sobre haber logrado un contacto efectivo solo con una minoría de sus estudiantes. Si se consideran las respuestas que están «bastante de acuerdo» se llega al 34\% de docentes. Si bien esta encuesta se aplicó a solo un mes del ASPO, la pauta es coincidente con relevamientos de gran escala hechos con posterioridad que constatan un alto nivel de continuidad pedagógica pese a la educación no presencial (ME-UNICEF, 2020). Nuevamente observamos que el sector de gestión y el NSE son las de más alta asociación (con diferencias porcentuales próximas a los 30 pp.): un 49\% de docentes de educación estatal y $45 \%$ de quienes trabajan en escuela de NSE bajo están bastante o muy de acuerdo con que solo se ha establecido comunicación con una minoría de estudiantes (Tabla X).

Por último, el acompañamiento de estudiantes es una interpelación de la política oficial de continuidad pedagógica. Cerca de la mitad de los encuestados/as está «bastante» o «muy de acuerdo» con haber podido acompañar y compartir gratos momentos con la mayoría de sus estudiantes (Tabla XI). Esta gratificación está más presente entre quienes se desempeñan en escuelas privadas $(59 \%$, con 22 pp. más que sus pares de escuelas estatales), de NSE medios y altos (59\%, con 18 pp. más que los de menores NSE), con tradición de uso de TIC antes del ASPO (55\%, con 15 pp. más que los que carecían de tal tradición) y que trabajaban en una sola institución ( $58 \%$, con 14 pp. más que los que se desempeñan en dos o más escuelas). 


\section{Tabla XI. Grado de acuerdo con la frase «Hemos podido acompañar y compartir momentos gratos con la mayoría de los/as estudiantes» según sector de gestión, NSE, recursos TIC en su escuela pre-ASPO y cantidad de escuelas donde trabaja. Docentes de nivel secundario del Área Metropolitana, 2020}

\begin{tabular}{|c|c|c|c|c|c|c|c|c|c|}
\hline \multirow[b]{2}{*}{$\begin{array}{l}\text { POSIBILIDAD DE ACOMPAÑAR Y } \\
\text { COMPARTIR MOMENTOS GRATOS } \\
\text { CON ALUMNOS/AS }\end{array}$} & \multirow[b]{2}{*}{ TOTAL } & \multicolumn{2}{|c|}{$\begin{array}{c}\text { SECTOR } \\
\text { DE GESTIÓN }\end{array}$} & \multicolumn{2}{|c|}{ NSE } & \multicolumn{2}{|c|}{$\begin{array}{l}\text { TENENCIA DE PLATAFORMA Y USO } \\
\text { PEDAGÓGICO DE TIC EN ACTIVIDADES } \\
\text { CON ESTUDIANTES ANTES DEL ASPO }\end{array}$} & \multicolumn{2}{|c|}{$\begin{array}{l}\text { CANTIDAD } \\
\text { DE ESCUELAS } \\
\text { DONDE TRABAJA }\end{array}$} \\
\hline & & Estatal & PRIVADO & $\begin{array}{c}\text { Bajo Y } \\
\text { Medio-Bajo }\end{array}$ & $\begin{array}{c}\text { MEdIO } \\
\text { Y MÁs ALTO }\end{array}$ & $\begin{array}{l}\text { SIN PLAT. } \\
\text { Y BAJO USO PEDAG. DE TIC }\end{array}$ & $\begin{array}{l}\text { CON PLATAFORMA O SIN } \\
\text { PLAT. PERO CON ALTO USO } \\
\text { DE APLICACIONES }\end{array}$ & 1 escuela & 2 o MÁs \\
\hline Nada de acuerdo & $13 \%$ & $18 \%$ & $9 \%$ & $17 \%$ & $8 \%$ & $18 \%$ & $8 \%$ & $9 \%$ & $15 \%$ \\
\hline Poco de acuerdo & $39 \%$ & $45 \%$ & $32 \%$ & $43 \%$ & $33 \%$ & $42 \%$ & $37 \%$ & $33 \%$ & $41 \%$ \\
\hline Bastante de acuerdo & $37 \%$ & $32 \%$ & $43 \%$ & $33 \%$ & $43 \%$ & $33 \%$ & $41 \%$ & $44 \%$ & $35 \%$ \\
\hline Muy de acuerdo & $11 \%$ & $6 \%$ & $16 \%$ & $8 \%$ & $16 \%$ & $7 \%$ & $13 \%$ & $14 \%$ & $10 \%$ \\
\hline N & 678 & 344 & 334 & 407 & 269 & 252 & 401 & 196 & 477 \\
\hline
\end{tabular}

Fuente: datos de nuestra encuesta a docentes (abril-mayo 2020).

\section{A manera de cierre}

Nuestra encuesta nos permitió mapear aspectos claves del teletrabajo forzado de docentes de nivel secundario del AMBA al inicio del confinamiento por COVID-19. Este análisis se nutrió del enfoque CyMAT y de estudios sobre el TT y busca aportar claves para entender algunos de los efectos que tuvo la emergencia educativa, así como reconocer variaciones y especificidades según las condiciones institucionales, laborales y personales en las que se desplegaron.

En primer lugar, caracterizamos las condiciones materiales básicas y la extensión de la jornada laboral en el nuevo escenario de teletrabajo. Por un lado, nuestra encuesta mostró que sólo la mitad de los/as docentes contaba con espacio aislado y acceso a computadora de uso exclusivo — recursos básicos para sostener la política de continuidad pedagógica y para mitigar los efectos negativos que el TT docente forzado conllevó. Los/as docentes que tienen una mejor situación relativa son los que se desempeñan en escuelas privadas y con alumnados de altos niveles socioeconómicos, que residen en hogares sin menores y tienen menores niveles de responsabilidad doméstica y de cuidado en sus hogares. De este conjunto de factores, el tipo de familia y de responsabilidades en el hogar presentaron mayor asociación con la dotación de recursos para el teletrabajo. Las desiguales características de los hogares definieron aspectos claves de los modos en que los/as docentes pudieron adaptarse a la emergencia. Así, la virtualización de la educación recayó en los/as docentes que enfrentaron con lo que tenían demandas políticas, institucionales y profesionales. Por otro lado, este trabajo evidenció que el TT en confinamiento fue acompañado por la percepción de una muy significativa ampliación de la jornada laboral por la gran mayoría de los/as docentes, siendo más fuerte esta vivencia entre docentes de escuelas privadas que trabajan con población de NSE medio-alto y alto. Estas diferencias se vincularían al mayor uso de TIC previo al ASPO en las escuelas privadas, sumado a las mejores condiciones materiales y de equipamiento informático y conectividad en los hogares de sus estudiantes, y a las presiones que llegan a las escuelas por parte de las familias para sostener actividades pedagógicas.

En segundo lugar, nuestro análisis se organizó en torno a los factores relacionales y psicosociales del trabajo docente, prestando atención a cuestiones organizacionales y también a la carga mental y psíquica que el TT implicó. Así, mostramos que la gran mayoría de los/as docentes no participaron en decisiones colegiadas respecto de su tarea durante la emergencia, y que tuvieron dificultades para reflexionar con 
otros/as. Se evidenciaron escenarios muy contrastantes en términos de acompañamiento tecnológico y pedagógico por parte de pares y del equipo de conducción (con situaciones levemente favorables para el caso de las escuelas privadas, las que usaban TIC previo al ASPO y las que tenían un estudiantado de NES medio y alto, factores estrechamente asociados entre sî). La evidencia aportada por este estudio muestra condiciones de trabajo muy diferentes para encarar la educación de emergencia en esta primera etapa, las cuales pendulan entre el aislamiento y la integración de los/as docentes en la organización (ya sea para aprender nuevas tecnologías como para definir sus acciones educativas), en contextos donde en la mayoría de los casos la toma de decisiones de aspectos centrales del trabajo escolar fue asumida por el equipo de conducción (siendo marginalizadas formas de toma de decisión colegiadas). Estos variados escenarios fueron acompañados por desiguales niveles de autonomía profesional, sensación de aislamiento para reflexionar sobre la emergencia y niveles de acompañamiento de pares y autoridades muy disímiles.

En cuanto a la carga mental y psíquica del teletrabajo docente, nuestra encuesta nuevamente evidencia escenarios muy contrastantes: alrededor de mitad de los/as docentes estaban desbordados por tener que trabajar con colegas usando TIC (siendo los estatales los que tenían mayor carga mental relativa y los que estaban en escuelas con NSE bajo y medio-bajo) y por tener que virtualizar sus clases (siendo los/as de escuelas privadas y los/as que trabajaban con población de NSE medio-alto y alto los/as que tenían mayor carga psíquica). Asimismo, la encuesta muestra que la mitad de los/as docentes se sentían presionados/as para virtualizar el trabajo sin contar con formación ni herramientas para hacerlo (siendo los/as que trabajaban en escuelas con más bajo uso de TIC antes del ASPO las que tenían mayor carga mental relativa, como así también aquellos/as que trabajaban en escuelas estatales). La mayor carga mental en estas dimensiones no sólo tenía que ver con atributos institucionales y sociales sino también personales, laborales y familiares (los cuales nos permitieron caracterizar un panorama complejo y multifacético). Por último, nuestro interés en los aspectos sociales del trabajo docente nos llevó a examinar cómo veían los/ as docentes el impacto de su tarea en las trayectorias escolares, y con ello, cómo entendían que estaban cumpliendo con su responsabilidad social como educadores. En este caso, nuestros datos muestran diferencias significativas, pero también continuidades entre las percepciones de los/as docentes de diferentes tipos de escuela, poblaciones e incluso condiciones de vida. En relación con el abandono, casi la mitad de los/as docentes expresaba su preocupación por el impacto que la educación en emergencia iba a tener en la deserción de sus estudiantes (siendo esta preocupación mucho más fuerte en el caso de los/as docentes de escuelas estatales y que trabajaban con población de NSE bajo y medio-bajo). En cambio, la mayoría de los/as docentes de ambos sectores acordaban que habían podido comunicarse con sus estudiantes (a pesar las fuertes diferencias en sus condiciones de trabajo y en sus organizaciones). La mayoría de los/ as docentes que no lograron comunicarse trabajaban en escuelas estatales y con jóvenes de NSE bajo y medio-bajo. En cuanto al acompañamiento de sus estudiantes (imperativo de política instalado por la continuidad pedagógica), se aprecian sostenidas diferencias entre grupos de docentes: cerca de la mitad creía haber podido acompañar y compartir gratos momentos con sus estudiantes, siendo estas situaciones más frecuentes en las escuelas privadas, con tradición de uso TIC antes del ASPO y que trabajaban en una sola institución.

$\mathrm{Al}$ considerar las condiciones estructurales y psicosociales del trabajo docente junto con la percepción que tenían los/as docentes sobre su rol en el sostenimiento de las trayectorias escolares, es posible reconocer dos configuraciones diferentes de acuerdo con el sector de gestión de la escuela y al NSE del alumnado. Las y los docentes de escuelas privadas y con alumnados de mayores NSE contaron con mayo- 
Teletrabajo docente durante el confinamiento por COVID-19 en Argentina. Condiciones materiales y perspectivas sobre la carga de trabajo, la responsabilidad social y la toma de decisiones

res recursos para enfrentar el imperativo de la virtualización pedagógica — debido a la experiencia previa en el uso de TIC en sus escuelas antes del ASPO_- pero a la vez identificaron un empeoramiento de sus condiciones de trabajo en términos de una mayor ampliación del tiempo de trabajo y de mayores niveles de carga psíquica y mental (con la sola excepción del indicador que apuntaba a relevar la mayor presión que sintieron por virtualizar su propuesta pedagógica sin contar con formación y herramientas para ello). No obstante, tenían expectativas relativamente buenas respecto del aprendizaje de sus estudiantes. En contraste, las y los docentes de escuelas estatales con alumnados de más bajo NSE tendían a trabajar en escuelas con menor experiencia en el uso de TIC antes del ASPO, lo cual convergía con la mayor percepción de sentirse presionados a virtualizar su trabajo pedagógico al inicio del ASPO sin contar con formación específica, apoyos pedagógicos ni herramientas suficientes para cumplir con las demandas de la CP. Si bien ellos/as no percibieron una intensificación de la jornada tan alta como sus pares del sector privado, plantearon mayores dudas sobre la eficacia de su acción educativa para sostener la CP de muchos estudiantes sin conectividad y que tuvieron poco vínculo con la escuela al inicio del ASPO — lo cual puede ser interpretado también como una sobre carga psíquica (en términos negativos) ya que expresa que aspectos claves de la identidad profesional docente estaban siendo cuestionados por la distancia social, física y pedagógica de muchos/as estudiantes.

Como vimos, la irrupción forzada del teletrabajo se desplegó en un escenario institucional y social fuertemente marcado por desigualdades, el cual impactó en una fuerte diferenciación de las vivencias y experiencias que los/as docentes en la primera etapa del confinamiento - momento en el que no existía ningún marco legal que regulara la extensión, características, deberes y responsabilidades del TT. Nuestro trabajo abona al conocimiento colectivo que se está forjando para entender la complejidad del TT docente forzado en contextos de persistente segmentación educativa.

\section{Referencias bibliográficas}

AIT (Academia Internacional de Teletrabajo-Capítulo América Latina y el Caribe) (2017): Primer Informe sobre el Estado del Teletrabajo en América Latina y el Caribe (en línea). https: / www.ita-lac.org/docs/1er-Informe-Estado-del-Teletrabajo-LATAM.pdf, consultado el 9 de septiembre de 2020.

Ardini, Claudia; Herrera, María Montserrat; González Angeletti, Valeria y Secco, Nadir, Emmanuel (2020): "Docencia en tiempos de coronavirus: una mirada al trabajo docente y la experiencia educativa en entornos virtuales en el marco del ASPO por la pandemia COVID-19". Mutual Conexión. Facultad de Ciencias de la Comunicación Universidad Nacional de Córdoba (en línea). http:/ / transmediacordoba.org.ar/ covid-19-la-experiencia-educativa-en-el-contexto-de-la-pandemia/, consultado el 14 de septiembre de 2020.

Bascia, Nina y Rottmann, Cindy (2011): “What's so Important About Teachers' Working Conditions? The Fatal Flaw in North American Educational Reform". Journal of Education Policy, 26 (6), 787-802 (en línea). DOI: https://doi.org/10.1080/02680939.2010.543156, consultado el 14 de septiembre de 2020.

Burkhauser, Susan (2017): "How Much Do School Principals Matter When it Comes to Teacher Working Conditions?". Educational Evaluation and Policy Analysis, (39) (1), 126-145 (en línea). DOI: https://doi. org/10.3102/0162373716668028, consultado el 14 de septiembre de 2020. 
Teletrabajo docente durante el confinamiento por COVID-19 en Argentina. Condiciones materiales y perspectivas sobre la carga de trabajo, la responsabilidad social y la toma de decisiones

Cardini, Alejandra; D’Alessandre, Vanesa y Torre, Esteban (2020). Educar en tiempos de pandemia. Respuestas provinciales al COVID-19 en Argentina. Buenos Aires: CIPPEC.

Chequeando (2020): “¿Qué es el AMBA, la zona más afectada del país por el coronavirus?”. Chequeado (en línea). https://chequeado.com/hilando-fino/que-es-el-amba-la-zona-mas-afectada-del-pais-encoronavirus/, consultado el 14 de septiembre de 2020.

Cifuentes-Leiton, Diana Milec (2020): "Teletrabajo en dos tiempos psicosociales: gobierno, empleadores y teletrabajadores". Desarrollo Gerencial, 12 (2), 1-25 (en línea). DOI: https://doi.org/10.17081/ dege.12.2.3913, consultado el 14 de septiembre de 2020.

Conner, M.; Fletcher, W.; Firth-Cozens, J. y Collins, S (1994): “Teleworking, Stress and Health”. Health psychology: Potential in diversity, 309-313.

CTERA (2020): "Salud y condiciones de trabajo docente en tiempos de emergencia sanitaria COVID19". Informe de la Encuesta Nacional de CTERA (en línea). https:/ /www.ctera.org.ar/index.php/salud-labo$\mathrm{ral} /$ publicaciones/item/3611-informe-de-la-encuesta-ncional-de-ctera-salud-y-condiciones-de-trabajo-docente-en-tiempos-de-emergencia-sanitaria-covid19, consultado el 9 de septiembre de 2020.

Cucchiara, Maia Bloomfield; Rooney, Erin y Robertson-Kraft, Claire (2015): “I’ve Never Seen People Work so Hard! Teachers' Working Conditions in the Early Stages of School Turnaround". Urban Education, 50 (3), 259-287 (en línea). DOI: https://doi.org/10.1177/0042085913501896, consultado el 9 de septiembre de 2020 .

Cuenca, Ricardo; Fabara Garzón, Eduardo; Parra Garrido, Manuel; Tomasina, Fernando; Rodríguez Guzmán, Lucía; Kohen, Jorge y Ecuadro. Centro Nacional de Investigaciones Sociales y Educativas-CENAISE (2009). Condiciones de trabajo y salud docente. Estudios de casos en Argentina, Chile, México, Perú y Uruguay. Santiago de Chile, OREALC/UNESCO.

Da Silva, Avelino Francisco (2000): “O teletrabalho, uma forma de transformação do emprego". Scripta Nova: revista electrónica de geografía y ciencias sociales, (4), 61.

Dabenigno, Valeria; Meo, Analía Inés; y Freytes Frey, Ada (2020): Informe Nro. 1. Preguntas de investigación y caracterización de docentes de secundaria encuestados/as durante el ASPO 2020 (en línea) https://sway.office. com/BspUfPqfZWmy73wg, consultado 20 de noviembre de 2020.

De Luis, Pilar; Martínez, Ángel; Pérez, Manuela; Vela, Maria José y Abella, Silvia (2006): "El Teletrabajo como factor de mejora medioambiental. Efectos indirectos en la vida de las mujeres" en Documento de trabajo. Zaragoza: Universidad de Zaragoza.

Di Piero, Emilia y Miño Chiappino, Jessica (en prensa): "Pandemia, desigualdad y educación en Argentina: un estudio de las propuestas a nivel subnacional" en S. Herrera, G. Gutiérrez Cham, y Jochen Kemner: El impacto COVID-19 en América Latina y el Caribe. Guadalajara: Centro de Estudios Latinoamericanos Avanzados (CALAS).

Dirié, Cristina y Pascual, Liliana (2014): "La rama de enseñanza en la Provincia de Buenos Aires: Evolución reciente y condiciones laborales" en Suarez Maestre y Chicatún (comp.): Las condiciones de trabajo en la provincia de Buenos Aires. La Plata: Ministerio de Trabajo de la Provincia de Buenos Aires. Serie de Estudios, (2) 2. 
Teletrabajo docente durante el confinamiento por COVID-19 en Argentina. Condiciones materiales y perspectivas sobre la carga de trabajo, la responsabilidad social y la toma de decisiones

Eurofound - International Labour Office (2017): "Working Anytime, Anywhere: The Effects on the World of Work". Publications Office of the European Union, Luxembourg, and the International Labour Office, Geneva (en línea). DOI: https://doi.org/10.2806/372726, consultado el 9 de septiembre de 2020.

Expósito, Cristián David y Marsollier, Roxana Graciela (2020): "Virtualidad y educación en tiempos de COVID-19. Un estudio empírico en Argentina”. Educación y Humanismo, 22 (39) (en línea). DOI: https://doi.org/10.17081/eduhum.22.39.4214, consultado el 9 de septiembre de 2020.

Ezpeleta, Justa (1989). Escuelas y maestros: condiciones del trabajo docente en la Argentina. Santiago de Chile: Editorial Universitaria.

Fernández Tapia, Joselito y Bravo Salazar, Rocío Guadalupe (2019): "El teletrabajo en América Latina: derecho de segunda y cuarta generación y de ciudadanía digital". Crítica y Resistencias: Revista de conflictos sociales latinoamericanos, (9), 17-38.

Firestone, William A. y Pennell, James R. (1993): “Teacher Commitment, Working Conditions, and Differential Incentive Policies." Review of Educational Research, 63 (4), 489-525 (en línea). DOI: https://doi. org/10.3102/00346543063004489, consultado el 10 de septiembre de 2020.

Giraudo, Esther; Korinfeld, Silvia y Mendizábal, Nora (2003): “Trabajo y salud: un campo permanente de reflexión e intervención" en H. Daniel Dei y Noma Menna (eds.): De los recursos humanos a la gestión con el personal. Una nueva mirada de los vínculos en las organizaciones. Buenos Aires: Editorial Docencia.

Geiger, Tray y Pivovarova, Margarita (2018): "The Effects of Working Conditions on Teacher Retention". Teachers and Teaching, 24 (6), 604-625. DOI: https://doi.org/10.1080/13540602.2018.1457524.

Guaca, Nancy Amparo; Caicedo, Yudith y Díaz Dávila, Juan Carlos (2018): “Estado del arte de Teletrabajo". Documentos de trabajo ECACEN, (1). DOI: https://doi.org/10.22490/ECACEN.2568.

Jiménez Bernardino, Ángel Ernesto (2013): “Análisis comparativo de normativas de teletrabajo en América Latina/Comparison of Telework Policy in Latin America”. RIDE Revista Iberoamericana para la Investigación y el Desarrollo Educativo, 4 (7), 200-222.

Ladd, Hellen F. (2011): “Teachers' Perceptions of their Working Conditions: How Predictive of Planned and Actual Teacher Movement?". Educational Evaluation and Policy Analysis, 33 (2), 235-261 (en línea). DOI: https://doi.org/10.3102/0162373711398128, consultado 25 de setiembre 2020.

Meo, Analía Inés (2020): "Impact of COVID-19 on Secondary School Teaching in Argentina". Discover Society, May (en línea). https://discoversociety.org/2020/05/06/impact-of-covid-19-on-secondaryschool-teaching-in-argentina/, consultado 20 de setiembre 2020.

Meschengieser, Carolina; Iñigo, Luisa y Caderosso, Melina (2018). Contribuciones para pensar la equidad educativa en el Nivel Secundario en la Ciudad Autónoma de Buenos Aires. Unidad de Evaluación Integral de la Calidad y Equidad Educativa, Ministerio de Educación e Innovación, GCABA. (en línea). https://www. buenosaires.gob.ar/sites/gcaba/files/ueicee2018_contribuciones_para_pensar_la_equidad_educativa_en_el_nivel_secundario.pdf, consultado el 14 de septiembre de 2020.

Miano, Amalia (2012). Cuando el trabajo entra al hogar. Las nuevas tecnologías sobre las calificaciones profesionales en la modalidad de teletrabajo. Saarbrücken: Editorial Académica Española. 
Teletrabajo docente durante el confinamiento por COVID-19 en Argentina. Condiciones materiales y perspectivas sobre la carga de trabajo, la responsabilidad social y la toma de decisiones

Ministerio de Educación, Cultura, Ciencia y Tecnología de la Nación (ME) (2018). Anuario Estadístico Educativo. Ciudad Autónoma de Buenos Aires (en línea). https://www.argentina.gob.ar/sites/default/files/ anuario-estadistico-datos-2018-web.pdf, consultado el 10 de septiembre de 2020.

Ministerio de Educación de la Nación (ME) (2020). Informe preliminar de Encuesta a Docentes. Continuidad pedagógica en el marco del aislamiento por COVID-19. Ministerio de Educación de la Nación. Ciudad Autónoma de Buenos Aires (en línea). https://www.argentina.gob.ar/sites/default/files/informe_preliminar_encuesta_a_docentes_enpcp.pdf, consultado el 14 de septiembre de 2020.

Ministerio de Educación de la Nación-UNICEF (ME-UNICEF) (2020). Informe preliminar de Encuesta a Hogares. Continuidad pedagógica en el marco del aislamiento por COVID-19. Ministerio de Educación y UNICEF, Ciudad Autónoma de Buenos Aires (en línea). https://www.argentina.gob.ar/sites/default/files/informe_preliminar_encuesta_a_hogares.pdf, consultado el 14 de septiembre de 2020 .

Neffa, Julio César(1988). ¿Qué son las Condiciones y Medio Ambiente de Trabajo? Propuesta de una nueva perspectiva. Buenos Aires: Humanitas.

Quintero, Silvina; Antón, Gustavo; Cutufia, Laura; Abelenda, Norberto; Moroni, Martín; Marquetti, Roberto y González, Walter (2019). Documento metodológico Índice de Condiciones Básicas de la Calidad Edilicia (ICBCE). Buenos Aires: UEICEE (en línea). https://www.buenosaires.gob.ar/sites/gcaba/files/ueicee_doc_metod_icbce.pdf, consultado el 14 de setiembre 2020.

Rocha, Cháris Telles Martins da y Amador, Fernanda Spanier (2018): "O teletrabalho: conceituação e questões para análise”. Cadernos EBAPE.BR, 16(1), 152-162 (en línea). DOI: https://dx.doi. org/10.1590/1679-395154516, consultado el 9 de septiembre de 2020.

Rodríguez, Alejandro Damián y D’errico, Julieta (2017): “Teletrabajadores: entre los discursos optimistas y los contextos precarizados. Una aproximación desde el caso argentino". Revista Colombiana de Sociología, 40 (2), 47-66 (en línea). DOI: http://dx.doi.org/10.15446/rcs.v40n2.66384, consultado el 9 de septiembre de 2020 .

Página 12 (2019): "Explotó otra estufa en una escuela de Moreno". Página 12 (en línea). https:/ /www.pagina12.com.ar/195164-exploto-otra-estufa-en-una-escuela-de-moreno, consultado el 14 de septiembre de 2020 .

Spillane, James P. (2010): "A Distributed Perspective on School Leadership and Management". International Encyclopedia of Education, 1-6. DOI: https://doi.org/10.1016/B978-0-08-044894-7.00438-3, consultado el 9 de septiembre de 2020.

Tremblay, Diane-Gabrielle (2003): “Telework: A New Mode of Gendered Segmentation? Results From a Study in Canada". Canadian Journal of Communication, 28 (4), 461-478. DOI: https://doi.org/10.22230/ cjc.2003v28n4a1393, consultado el 9 de septiembre de 2020.

Zamora, Begoña (2011): "Voces y miradas del y sobre el profesorado". Revista de Sociología de la Educación-RASE, 4(3), 333-365. 


\section{Anexo 1}

Cuadro 1. Porcentaje de mujeres docentes por jurisdicción y sector de gestión. CABA y PBA

\begin{tabular}{lcccccc}
\hline \% MUJERES & $\begin{array}{c}\text { AMBOS SECTORES } \\
\text { CENPE 2014 }\end{array}$ & $\begin{array}{c}\text { AMBOS SECTORES. } \\
\text { ENCUESTA EDES } \\
\text { COVID-19 }\end{array}$ & $\begin{array}{c}\text { SECTOR ESTATAL } \\
\text { CENPE 2014 }\end{array}$ & $\begin{array}{c}\text { SECTOR ESTATAL. } \\
\text { ENCUESTA EDES } \\
\text { COVID-19 }\end{array}$ & $\begin{array}{c}\text { SECTOR PRIVADO } \\
\text { CENPE 2014 }\end{array}$ & $\begin{array}{c}\text { SECTOR PRIVADO. } \\
\text { ENCUESTA EDES } \\
\text { COVID-19 }\end{array}$ \\
\hline PBA & $68 \%$ & $75 \%$ & $69 \%$ & $76 \%$ & $64 \%$ & $75 \%$ \\
\hline CABA & $61 \%$ & $68 \%$ & $59 \%$ & $64 \%$ & $64 \%$ & $76 \%$ \\
\hline
\end{tabular}

Fuente: Censo Nacional del Personal Docente y no Docente del sistema educativo argentino 2014 y encuesta EDES-COVID19 2020.

Cuadro 2. Promedio de edad de docentes según jurisdicción y sector de gestión. CABA y PBA

\begin{tabular}{lcccccc}
\hline $\begin{array}{c}\text { PROMEDIO } \\
\text { DE EDAD }\end{array}$ & $\begin{array}{c}\text { AMBOS SECTORES } \\
\text { CENPE 2014 }\end{array}$ & $\begin{array}{c}\text { AMBOS SECTORES. } \\
\text { ENCUESTA EDES } \\
\text { COVID- 19 }\end{array}$ & $\begin{array}{c}\text { SECTOR ESTATAL } \\
\text { CENPE 2014 }\end{array}$ & $\begin{array}{c}\text { SECTOR ESTATAL. } \\
\text { ENCUESTA EDES } \\
\text { COVID-19 }\end{array}$ & $\begin{array}{c}\text { SECTOR PRIVADO } \\
\text { CENPE 2014 }\end{array}$ & $\begin{array}{c}\text { SECTOR PRIVADO. } \\
\text { ENCUESTA EDES } \\
\text { COVID- 19 }\end{array}$ \\
\hline PBA & $49 \%$ & $47 \%$ & $49 \%$ & $47 \%$ & $47 \%$ & $47 \%$ \\
\hline CABA & $47 \%$ & $43 \%$ & $47 \%$ & $43 \%$ & $46 \%$ & $42 \%$ \\
\hline
\end{tabular}

Fuente: Censo Nacional del Personal Docente y no Docente del sistema educativo argentino 2014 y encuesta EDES-COVID19 2020.

\section{Notas biográficas}

Analía Inés Meo es Licenciada en Sociología (Universidad de Buenos Aires -UBA) y Doctora en Sociología (Universidad de Warwick, Reino Unido). Es investigadora del Consejo Nacional de Investigaciones Científicas y Técnicas y su sede de trabajo es el Instituto de Investigaciones Gino Germani, Facultad de Ciencias Sociales (UBA). También es integrante de INCLUIR. Instituto para la Inclusión social y el Desarrollo Humano (asociación civil). Realiza investigaciones en el campo de la sociología de la educación. Sus temas de interés son el trabajo docente, sus regulaciones e identidades laborales; la puesta en acto de las políticas educativas; y las disputas simbólicas y sociales en el campo escolar. La mayoría de sus análisis se centran en el nivel secundario en escuelas comunes y alternativas en la Ciudad Autónoma de Buenos Aires. Es docente de grado y postgrado en las áreas de sociología de la educación e investigación visual.

Valeria Dabenigno es Lic. en Sociología y Mg. en Ciencias Sociales del Trabajo de la Universidad de Buenos Aires (UBA). Actualmente es investigadora visitante del Instituto de Investigaciones Gino Germani de la Facultad de Ciencias Sociales de esa universidad, donde codirige el proyecto «La producción social de identidades laborales y de género de docentes de escuelas técnicas en la Ciudad Autónoma de Buenos Aires». También se desempeña como profesora de Metodología y técnicas de la Investigación Social I, II y III de la misma facultad. Dentro del campo de la Sociología de la Educación, sus investigaciones recorren temas variados: la puesta en práctica de políticas educativas, el trabajo e identidades docentes y trayectorias educativo-laborales de docentes de nivel secundario, así como otros estudios sobre orientaciones de futuro, involucramiento escolar y experiencia escolar de estudiantes secundarios. Ha coordinado equipos y área de investigación en ámbitos de gobierno de la educación. 